\title{
Reduction in parvalbumin expression not loss of the parvalbumin-expressing GABA interneuron subpopulation in genetic parvalbumin and shank mouse models of autism
}

Federica Filice ${ }^{1}$, Karl Jakob Vörckel ${ }^{2}$, Ayse Özge Sungur², Markus Wöhr ${ }^{2}$ and Beat Schwaller ${ }^{1 *}$

\begin{abstract}
Background: A reduction of the number of parvalbumin (PV)-immunoreactive $\left(P V^{+}\right)$GABAergic interneurons or a decrease in PV immunoreactivity was reported in several mouse models of autism spectrum disorders (ASD). This includes Shank mutant mice, with SHANK being one of the most important gene families mutated in human ASD. Similar findings were obtained in heterozygous (PV+/-) mice for the Pvalb gene, which display a robust ASD-like phenotype. Here, we addressed the question whether the observed reduction in PV immunoreactivity was the result of a decrease in PV expression levels and/or loss of the PV-expressing GABA interneuron subpopulation hereafter called "Pvalb neurons". The two alternatives have important implications as they likely result in opposing effects on the excitation/inhibition balance, with decreased PV expression resulting in enhanced inhibition, but loss of the Pvalb neuron subpopulation in reduced inhibition.
\end{abstract}

Methods: Stereology was used to determine the number of Pvalb neurons in ASD-associated brain regions including the medial prefrontal cortex, somatosensory cortex and striatum of PV-/-, PV+/-, Shank1-/- and Shank3B-/mice. As a second marker for the identification of Pvalb neurons, we used Vicia Villosa Agglutinin (WA), a lectin recognizing the specific extracellular matrix enwrapping Pvalb neurons. PV protein and Pvalb mRNA levels were determined quantitatively by Western blot analyses and qRT-PCR, respectively.

Results: Our analyses of total cell numbers in different brain regions indicated that the observed "reduction of $\mathrm{PV}^{+}$ neurons" was in all cases, i.e., in PV+/-, Shank1-/- and Shank3B-/- mice, due to a reduction in Pvalb mRNA and PV protein, without any indication of neuronal cell decrease/loss of Pvalb neurons evidenced by the unaltered numbers of $\mathrm{WA}^{+}$neurons.

Conclusions: Our findings suggest that the PV system might represent a convergent downstream endpoint for some forms of ASD, with the excitation/inhibition balance shifted towards enhanced inhibition due to the downregulation of PV being a promising target for future pharmacological interventions. Testing whether approaches aimed at restoring normal PV protein expression levels and/or Pvalb neuron function might reverse ASD-relevant phenotypes in mice appears therefore warranted and may pave the way for novel therapeutic treatment strategies.

Keywords: Parvalbumin, Shank1, Shank3, Autism, Perineuronal net, Calcium-binding protein, Calcium homeostasis

\footnotetext{
* Correspondence: Beat.Schwaller@unifr.ch

'Anatomy, Department of Medicine, University of Fribourg, Route

Albert-Gockel 1, CH-1700 Fribourg, Switzerland

Full list of author information is available at the end of the article
} 


\section{Background}

Autism spectrum disorders (ASD) consist of a group of heterogeneous neurodevelopmental disorders, with a high prevalence of $\sim 1 / 100$ children [1]. Core symptoms of ASD are deficits in social interaction and communication, together with restricted interests and repetitive behaviors [2-4]. The etiology of ASD remains unclear, but a strong genetic component is evident. ASD candidate genes are often implicated in synaptic transmission, are part of synapse formation/maintenance and/or affect the neurodevelopment during particular moments, e.g., during the "critical period" $[5,6]$. Functionally, these changes affect the excitation/inhibition (E/I) balance and subsequently influence network properties [7, 8].

One of the most important gene families mutated in ASD is the SHANK gene family [9], coding for multidomain scaffolding proteins located in the postsynaptic density of glutamatergic synapses [10]. In individuals with ASD or schizophrenia patients with ASD traits, mutations were repeatedly reported for all SHANK gene family members [4, 9, 11, 12], namely SHANK1 [13], SHANK2 [14-16] and SHANK3 [17-21]. Moreover, SHANK3 haploinsufficiency has been found in patients affected by the Phelan-McDermid 22q13 deletion mental retardation syndrome [22-25], often characterized by ASD features [26]. Importantly, mutations of SHANK genes were detected in the whole spectrum with a gradient in severity in mental retardation. Specifically, SHANK1 mutations were found in individuals with ASD and normal intelligence, whereas SHANK2 and SHANK3 mutations were associated with mild and severe mental retardation, respectively [9]. Consistent with the important role of the SHANK gene family in ASD, genetic Shank mouse models display behavioral alterations with relevance to all human ASD core symptoms. Shank1 null mutant mice display social and communication deficits [27], alterations in repetitive behavior, with elevated self-grooming behavior, particularly in social situations [28], and a mixed cognitive phenotype resembling aberrant cognitive processing evident in some ASD cases $[29,30]$. Likewise in two Shank2 models, strong ASDrelated behavioral alterations are evident [17-19, 31, 32]. In the various Shank3 models severity of the ASD phenotype varies with genetic manipulation, with a comparatively mild phenotype in the Shank3 model lacking the ANK domain [33, 34], but strong phenotypes in the other models [35-37], see also [38-40].

In the process of brain development, GABAergic signaling plays an essential role. Thus, it is not surprising that its disturbance/disruption has been related to the pathogenesis of ASD [41, 42]. Investigations on the role of the GABAergic system during neurodevelopment, however, are impeded by the fact that GABAergic interneurons are made up of different subtypes displaying heterogeneous morphological and physiological features; in the hippocampus, up to 21 subtypes have been identified [43]. One way to classify GABAergic, e.g., cortical interneurons, is based on the expression of $\mathrm{Ca}^{2+}$-binding proteins such as parvalbumin (PV; gene symbol: PVALB), calbindin D-28k and calretinin [44]. Among these specific subpopulations, PV-expressing interneurons seem to be highly impacted in several neuropsychiatric disorders including schizophrenia, bipolar disorder and ASD [45]. While in none of the previous studies in humans the PVALB gene itself was found to be mutated, a reduction in the order of $20-25 \%$ in the number of $\mathrm{PV}$-immunoreactive $\left(\mathrm{PV}^{+}\right)$neurons has been reported in ASD individuals [46] and mouse ASD models [47], see Table S1 in [48]. However, so far the question was not thoroughly addressed as to what extent the reduction in $\mathrm{PV}^{+}$neurons was the result of improper neurodevelopment (e.g., altered GABA interneuron subtype), neuron loss (neuronal death) or PV down-regulation (mRNA and/or protein). This is of high relevance, since the alternatives likely have distinct and even opposing effects on the excitation/inhibition balance: while loss of the Pvalb neuron subpopulation is likely to result in reduced inhibition, decreased PV expression results in enhanced inhibition. The absence of PV in PV-/- Pvalb neurons does not affect basal synaptic transmission, but enhances facilitation $[49,50]$ and shortens delayed transmitter release [51]. This asynchronous release augmented in the presence of $\mathrm{PV}$ is assumed to be important to desynchronize large fractions of local networks and prevent/disrupt excessive synchronized activity [52]. In line the observed increased regularity of spiking of PV-/- striatal Pvalb FSI in vitro [53], the appearance of synchronous $160-\mathrm{Hz}$ oscillations in the cerebellum of $\mathrm{PV}-/-$ mice in vivo [54] and facilitation of the $\mathrm{GABA}_{\mathrm{A}}$-ergic current reversal caused by high-frequency stimulation in $\mathrm{PV}-/$ hippocampal Pvalb FSI in vitro [55], all together provide evidence that PV plays a key role in the regulation of local inhibitory effects on pyramidal neurons, as well as on other interneurons (for more details, see [56]). Importantly, at the behavioral level, mice with reduced PV expression $(\mathrm{PV}+/-)$ or without $\mathrm{PV}(\mathrm{PV}-/-)$ display a robust ASD-like phenotype [48]. Although qualitative immunohistochemistry revealed no striking differences with respect to $\mathrm{VVA}^{+}$(putatively Pvalb) neurons in PV-/- mice $[55,57]$, a quantitative and systematic analysis of Pvalb neurons by unbiased stereology in different brain regions including ASD-implicated regions such as the medial prefrontal cortex (mPFC), somatosensory cortex (SSC) and striatum was still missing. Besides determining the number of Pvalb neurons in $\mathrm{PV}+/-$ and $\mathrm{PV}-/$ - mice, we quantified the number of this interneuron subpopulation in two well-established ASD mouse models, i.e., Shank1-/- and Shank3B-/- mice, 
covering the extremes of the spectrum with a gradient in severity in mental retardation.

\section{Methods \\ Animals}

All mice were group housed in temperature-controlled animal facilities $\left(24{ }^{\circ} \mathrm{C}, 12: 12 \mathrm{~h}\right.$ light/dark cycle), either at the University of Fribourg, Switzerland, or at the University of Marburg, Germany, and fed ad libitum. PV-deficient (PV-/-; strain name: B6.Pvalb ${ }^{\text {tm1Swal }}$ ) mice were generated by homologous recombination as previously described [58] and are considered as congenic with $\mathrm{C} 57 \mathrm{Bl} / 6 \mathrm{~J}$ [59]. C57Bl/6 J wild-type (WT) mice were used to generate the heterozygous $\mathrm{PV}+/$ - group. In some experiments mice expressing EGFP in the Pvalb neurons (line B6.Tg(Pvalb-EGFP)1Hmon [53]) were used. Shank1-/- mice (B6.129S4-Shank $1^{\text {tm1Shng } / J) ~}$ were generated in the laboratory of M. Sheng (29).

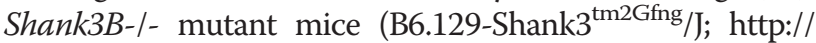
jaxmice.jax.org/strain/017688.html) were purchased from The Jackson Laboratory (Bar Harbor, Maine, USA) and were initially generated by Peca and colleagues [36]. Genotypes were determined according to established and previously described protocols $[28,36,58]$. Only male animals were used in this study. All experiments were performed with permission of the local animal care committees (Canton of Fribourg, Switzerland; Regierungspräsidium Gießen, Germany) and according to the present Swiss/ Germany law and the European Communities Council Directive of 24 November 1986 (86/609/EEC).

\section{Tissue preparation and immunohistochemistry}

Mice at postnatal day 25 (PND25) were anesthetized (Esconarkon, Streuli Pharma AG, Uznach, Switzerland) and perfused with $0.9 \%$ saline solution followed by $4 \%$ PFA. Brains were removed and post-fixed for $24 \mathrm{~h}$ in 4 \% PFA before being cryopreserved in $30 \%$ sucroseTBS at $4{ }^{\circ} \mathrm{C}$. Coronal and sagittal sections were cut rostro-caudally using a freezing microtome (Frigomobil, Reichert-Jung, Vienna, Austria) and six series of equidistant sections were collected using stereological systematic random sampling principles (see below). Free-floating sections were first incubated with TBS $0.1 \mathrm{M}$ plus $0.4 \%$ Triton X-100 and $10 \%$ newborn calf serum (NBS) for $1 \mathrm{~h}$ at room temperature, then washed three times with TBS $0.1 \mathrm{M}$, and incubated with PV antibody (anti-rabbit PV25, Swant, Marly, Switzerland) at a dilution 1:1000 and Vicia Villosa Agglutinin (biotinylated-VVA, Reactolab, Servion, Switzerland); $10 \mu \mathrm{g} / \mathrm{ml}$ in TBS $0.1 \mathrm{M}$ plus $\mathrm{MgCl}_{2}, \mathrm{MnCl}_{2}, \mathrm{CaCl}_{2}$ (final salt concentration: $0.1 \mathrm{mM}$ ) overnight at $4{ }^{\circ} \mathrm{C}$. Sections were washed once with TBS, then twice with Tris- $\mathrm{HCl}$ and incubated protected from light at room temperature with anti-rabbit $\mathrm{Cy} 3$-conjugated antibody
(1:200 dilution) and Alexa488 streptavidin-conjugated antibody (1:200 dilution, Milan Analytic AG, Switzerland) in Tris- $\mathrm{HCl}$. Nuclei of fixed cells were stained with DAPI (1:500 dilution, LuBio Science GmbH, Luzern, Switzerland) in PBS 0.1 M. After rinsing, slides were coverslipped with Hydromount (National Diagnostics, Atlanta, Georgia, USA).

\section{Stereological quantification}

The optical fractionator method [60] was used to estimate the total number of parvalbumin-positive $\left(\mathrm{PV}^{+}\right)$ and Vicia Villosa Agglutinin-binding $\left(\mathrm{VVA}^{+}\right)$cells in brain regions of interest (ROIs) using the Stereo Investigator system (Version 11, MicroBrightField, Williston, VT, USA). The system was connected to a Zeiss Axioplan microscope coupled with a Hamamtsu Orca Camera and with a motorized $x-y$ stage (Ludl Electronic Products, LTD, NY, USA). ROIs were determined based on stereotactic coordinates provided by the Paxinos and Franklin atlas [61] at 1.78-1.18 from bregma for the medial prefrontal cortex (mPFC), 1.10 to $-0.46 \mathrm{~mm}$ from bregma for the striatum and $1.20-3.25 \mathrm{~mm}$ lateral to the midline for the somatosensory cortex (SSC). Counting was done on images obtained with oil immersion objective lenses (x100 $\mathrm{NA}=1.40$ and $\mathrm{x} 63 \mathrm{NA}=1.30$ ). Five animals derived from heterozygous breedings were analyzed per genotype, with mice from the same litter but different genotypes, i.e., littermate controls, being included.

\section{Counting criteria}

Sampling parameters are reported in Table $1 . \mathrm{VVA}^{+}$and $\mathrm{PV}^{+}$cells were counted independently and according to the following criteria: (1) Well visible DAPI-stained nucleus; (2) well-defined perineuronal net (PNN) with a web-/lattice-like morphology for $\mathrm{VVA}^{+}$cells; examples are shown in Fig. 1) and (3) PV staining surrounding the DAPI-stained nucleus for $\mathrm{PV}^{+}$cells. Section thickness was measured at every fifth sampling location, and the mean of all measurements was used in all computations. At each sampling location, the microscope was focused down through the disector sample to count any cell within that particular counting frame according to disector counting rules. Since the fractionator method does not require a measurement of tissue volume or any other dimensional quality, the cell number estimate is valid, even if the tissue volume changes during processing. The total number of cells $(\mathrm{N})$ in the ROIs was estimated as outlined by West et al. $[60,62]$ using the equation:

$$
\mathrm{N}=\sum \mathrm{Q}^{-} \mathrm{x}(1 / \mathrm{ssf}) \mathrm{x}(1 / \text { asf }) \mathrm{x}(1 / \mathrm{tsf}),
$$

where ssf, asf and tsf are referred to the sampling sample fraction, the area sampling fraction and the thickness 
Table 1 Stereological sampling parameters

\begin{tabular}{|c|c|c|c|c|c|c|c|c|c|}
\hline $\begin{array}{l}\text { Brain } \\
\text { region }\end{array}$ & $\begin{array}{l}\text { Cutting } \\
\text { plane }\end{array}$ & $\begin{array}{l}\text { No. of } \\
\text { sections }\end{array}$ & $\begin{array}{l}\text { Section } \\
\text { evaluation } \\
\text { interval }\end{array}$ & $\begin{array}{l}\text { Height of } \\
\text { disector }(\mu \mathrm{m})\end{array}$ & $\begin{array}{l}\text { Guard zone } \\
\text { height }(\mu \mathrm{m})\end{array}$ & $\begin{array}{l}\text { Counting frame } \\
\text { area }(\mu \mathrm{m})\end{array}$ & $\begin{array}{l}\text { Sampling grid } \\
\text { area }(\mu \mathrm{m})\end{array}$ & $\begin{array}{l}\text { Measured } \\
\text { section thickness } \\
\text { mean }(\mu \mathrm{m})\end{array}$ & CE \\
\hline mPFC & coronal & $4-5$ & 6 & 20 & 0.5 & $90 \times 70$ & $150 \times 200$ & 22.4 & $\begin{array}{l}C E_{m=1} 0.07 \leq C E \leq \\
C E_{m=0} 0.09\end{array}$ \\
\hline Striatum & coronal & $7-8$ & 6 & 20 & 0.5 & $110 \times 90$ & $300 \times 300$ & 23.0 & $\begin{array}{l}C E_{m=1} 0.06 \leq C E \leq \\
C E_{m=0} 0.09\end{array}$ \\
\hline SSC & sagittal & $10-12$ & 6 & 20 & 0.5 & $583.5 \times 335.6$ & $250 \times 250$ & 23.4 & $\begin{array}{l}C E_{m=1} 0.07 \leq C E \leq \\
C E_{m=0} 0.10\end{array}$ \\
\hline
\end{tabular}

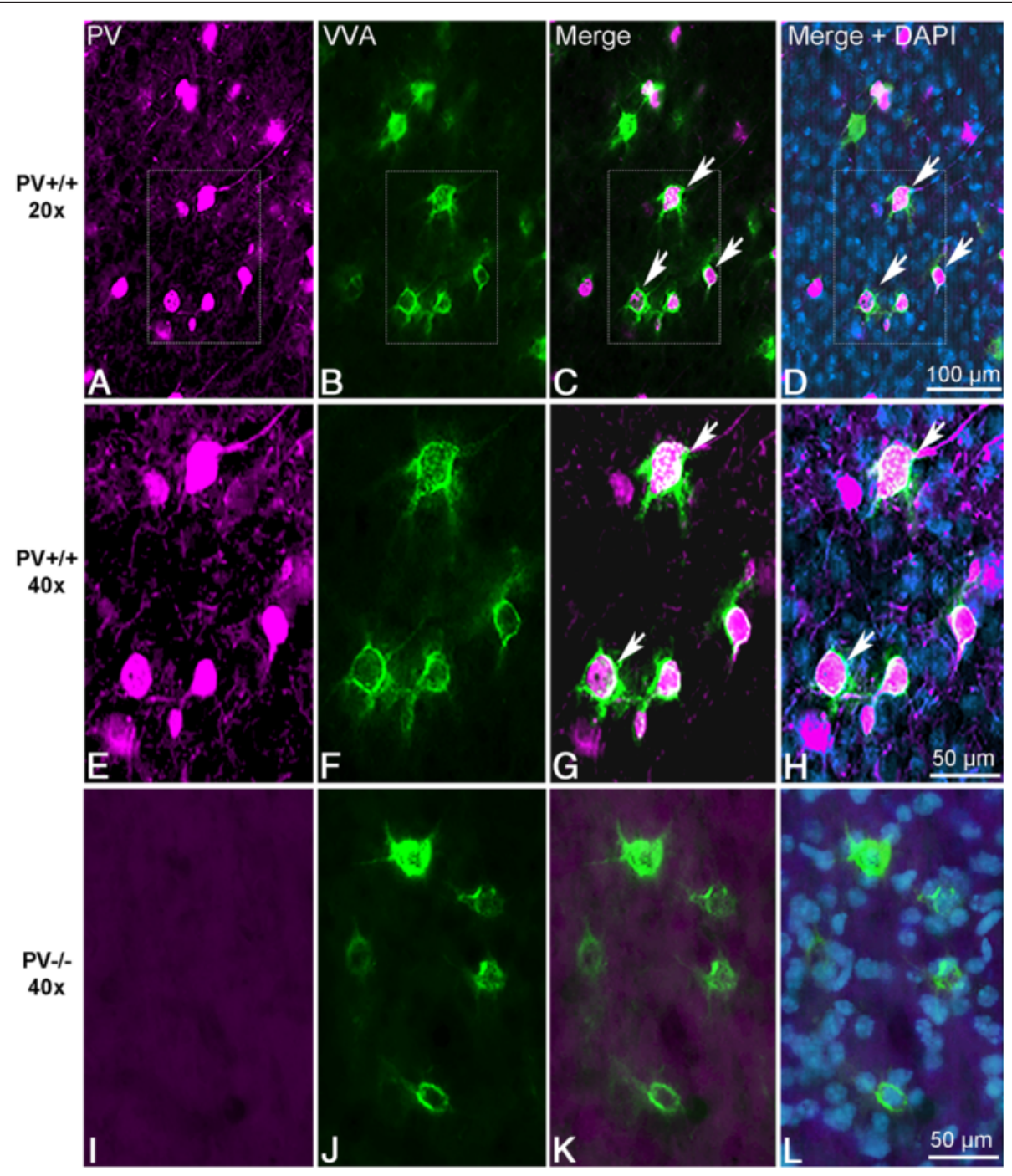

Fig. 1 Representative $\mathrm{PV}^{+}$and $\mathrm{WA}^{+}$cells from PND25 mouse cortex. a, b Single channel acquisition of (a) $\mathrm{PV}^{+}$(magenta) and (b) WA (green) cells. (c, d) Merged images showing PV (magenta) and WA (green) overlapping in the PND25 cortex of a WT mouse, in (d) additionally with DAPI (light blue) counterstaining. In $\mathrm{PV}^{+}$cell bodies (magenta), where most of the cell including the nucleus evidenced by DAPI staining (blue) was within the thickness of the section, the PNN (green) surrounding the cell was clearly visible. $\mathbf{a}-\mathbf{d}$ ) Low magnification and $\mathbf{e}-\mathbf{h}$ ) High magnification images. Arrowheads indicate the $\mathrm{PV}^{+} \mathrm{WA}{ }^{+}$double-positive neurons that are in focus. In the overlay image, the rim of the cells was lighting up in white, indicative for "co-localization" of PV and WA. i-I) High magnification images of PV+ (magenta) and WA+ (green) cells from PND25 PV-/mouse cortex. The morphology of PNNs in PV-/- animals does not differ from the one of WT mice. Scale bar: $100 \mu \mathrm{m}(\mathbf{a}-\mathbf{d}), 50 \mu \mathrm{m}(\mathbf{e}-\mathbf{I})$ 
sampling fraction, respectively. The precision of the estimates $\mathrm{N}$ is described by the coefficient of error $\mathrm{CE}$ (Table 1), which is the sampling error related to counting noise, systematic uniform random sampling and variances in section thickness [63]. A CE of 0.10 is generally accepted for most biological samples. CEs for both $m=1$ and $m=0$ are provided and are likely to bracket the true CEs of the estimates. Unlike in most double-labeling studies, strictly individual images for either $\mathrm{PV}^{+}$or $\mathrm{VVA}^{+}$structures were counted without crosschecking the other channel. In such a way, a cell, or more likely a cell segment resulting from the sectioning with "low" staining intensities (below the predefined threshold) and/or "atypical" shape (i.e., not easily discernable as cell-like) was considered negative, even if a check of the other channel would have identified this cell or cell segment as (likely also weakly) positive for the second marker.

\section{RT-qPCR}

Total RNA was extracted from mouse brain tissue using peqGold TRIzol reagent (Peqlab, VWR International $\mathrm{GmbH}$, Erlangen, Germany). cDNA was synthesized using Promega's reverse transcriptase kit (Promega AG, Dübendorf, Switzerland). qRT-PCR was carried out to examine the expression of mRNA of the $18 S$ rRNA and Pvalb genes using the universal 2X KAPA SYBR FAST qPCR Master Mix (Axonlab AG, Mont-sur-Lausanne, Switzerland). Details about the primer sequences are listed in Table 2. Gene expression quantitation was carried out in a DNA thermal cycler (Corbett Rotor gene 6000, QIAGEN Instruments AG, Hombrechtikon, Switzerland), according to the following two-steps protocol: a denaturation step of $95{ }^{\circ} \mathrm{C}$ for $3 \mathrm{~min}$; 40 cycles of denaturation at $95{ }^{\circ} \mathrm{C}$ for $3 \mathrm{~s}$ and annealing/extension/ data acquisition ranging from 60 to $62{ }^{\circ} \mathrm{C}$ for $20 \mathrm{~s}$. The housekeeping gene 18S ribosomal RNA (18S) was used as an endogenous control to normalize the mRNA content for each sample. Normalized mRNA levels were quantified by the $2-\Delta \Delta \mathrm{Ct}$ method [64].

\section{Western blot analyses}

Brains from euthanized mice were quickly removed, homogenized and soluble proteins extracted for Western blotting experiments as described before [65]. Proteins $(30 \mu \mathrm{g})$ were separated by SDS-PAGE (15\%). After electrophoresis, the proteins were transferred on nitrocellulose membranes (MS solution, Chemie Brunschwig, Basel, Switzerland). The membranes were then blocked in $5 \%$ non-fat milk in TBS-T for $60 \mathrm{~min}$ at room temperature and incubated with primary antibodies: rabbit anti PV25 (Swant, Marly, Switzerland), rabbit anti Calbindin D-28k (Swant, Marly, Switzerland) diluted 1:10,000 in $2 \%$ non-fat milk in TBS-T overnight at $4{ }^{\circ} \mathrm{C}$. Membranes were washed three times in TBS-T and incubated for $1 \mathrm{~h}$ with secondary antibody (goat antirabbit IgG HRP conjugated, Sigma-Aldrich, Buchs, Switzerland) diluted at 1:10,000 in TBS-T. Finally, membranes were repeatedly rinsed in TBS-T and developed using ECL (Merck Millipore, Schaffhausen, Switzerland). Bands visualized by ECL were quantified using Alpha VIEW SA software (California, USA). The levels of PV signals were normalized to calbindin D-28k (CB) signals, a protein previously shown to be unaltered in $\mathrm{PV}-/$ mice $[57,66]$ to control for differences in loading. CB levels were found to be unaltered in Shank1-/- and Shank3B-/- brains (data not shown). Alternatively the GAPDH signal on Western blots or the integral of the protein signals per sample of the Ponceau Red-stained membranes was used for normalization. No significant differences existed between PV signals quantitatively evaluated by either normalization method (not shown).

\section{Statistical analysis and cell number estimates}

mRNA and protein levels were compared between genotypes by the Student's $t$-test. Stereological data were analyzed using the GraphPad Prism software (San Diego, USA). Since no differences were encountered when comparing the ROIs of the two hemispheres in the same animal, data were pooled together and analyzed. The morphological data were first checked for normal distribution by the Kolmogorov-Smirnov test and then analyzed with a one-way ANOVA with genotype as factor. Tukey's test was performed as post hoc test. A p-value $<0.05$ was considered statistically significant.

\section{Results}

The numbers of $\mathrm{PV}^{+}$(Pvalb) interneurons are not changed in PV-reduced (PV+/-) and in PV-deficient (PV-/-) mice

Parvalbumin fast-spiking interneurons (PV-FSI) are preferentially ensheathed by perineuronal nets (PNNs) [67, 68] consisting of specialized extracellular matrix components

Table 2 qRT-PCR primers

\begin{tabular}{|c|c|c|c|c|}
\hline Primer & Sequence $5^{\prime}-3^{\prime}$ & Nt position & Gene & Gene accession number \\
\hline \multirow[t]{2}{*}{$18 \mathrm{~S}$ rRNA } & For: TCAAGAACGAAAGTCGGAGGTT & $1026-1047$ & Rn18s & NR_003278 \\
\hline & Rev: GGACATCTAAGGGCATCACAG & $1493-1513$ & & \\
\hline \multirow[t]{2}{*}{ PV } & For: TGTCGATGACAGACGTGCTC & $24-43$ & Pvalb & NM_013645 \\
\hline & Rev: TTCTTCAACCCCAATCTTGC & $309-328$ & & \\
\hline
\end{tabular}


that form a lattice-like structure around the somata and proximal dendrites of PV-expressing neurons. Various staining methods allow visualizing PNNs including Vicia Villosa Agglutinin (VVA), a lectin that binds to N-acetylgalactosamine residues of PNN components. $\mathrm{PV}^{+}$and VVA ${ }^{+}$cells were identified by fluorescent staining methods. Since neither the morphology nor the distribution of PNNs were shown to be altered in $\mathrm{PV}+/$ - and $\mathrm{PV}-/$ - mice in comparison to $\mathrm{PV}+/+$ mice $[57,69]$, VVA staining was used as reliable marker for visualizing the specific neuronal subpopulation of "PV-FSI" cells, defined as Pvalb neurons, irrespective of reduced or absent PV expression in PV +/- and PV-/- mice, respectively. Representative samples demonstrating the quality of the stainings for PV and VVA of PND25 PV $+/+$ and PV-/- mouse brains are depicted in Fig. 1. As expected and reported before [57], no positive staining for PV was detectable in the sections from PV-/- mice (Fig. 1).

Cell numbers were estimated using the optical fractionator method in three selected ROIs: the medial prefrontal cortex (mPFC), the somatosensory cortex (SSC) and the striatum of $\mathrm{PV}+/+, \mathrm{PV}+/-$ and $\mathrm{PV}-/$ - mice. $\mathrm{CE}$ values ranged from 0.06 to 0.10 (Table 1) indicating a sufficient precision of the estimates for both cell populations [63]. We observed a significant reduction in the number of $\mathrm{PV}^{+}$interneurons in $\mathrm{PV}+/-$ and $\mathrm{PV}-/$ - mice compared to $\mathrm{PV}+/+$ in all ROIs. On average, $\mathrm{PV}^{+}$cells in $\mathrm{PV}+/-$ mice were reduced to $60 \%$ of $\mathrm{PV}+/+$ controls; representative immunofluorescence images of mPFC from a WT and a PV+/- mouse are shown in Fig. 2a. The reduction in PV staining intensity in $\mathrm{PV}+/$ - samples is most striking by the decreased intensity of neuropil staining as previously observed in the temporal cortex (Fig. 2a in [57]). Evidently, the count in PV-/- cells was essentially zero. With respect to the number of $\mathrm{VVA}^{+}$ cells, no significant differences existed between all three genotypes and all three ROIs (Fig. 3a, left). An average of the three regions resulted in values of $98 \%$ and $99 \%$ of WT control for PV+/- and PV-/-, respectively, indicating that while PV expression levels were decreased, the number of Pvalb cells was unchanged (Table 3). Since expression of PV and PNNs are developmentally regulated, modulated by neuronal activity, e.g., during "sensitive" or "critical" periods, and moreover altered under pathological conditions (see discussion), we additionally used a transgenic mouse line, where EGFP is expressed under the control of the Pvalb promoter [53, 70] to estimate the number of Pvalb cells. Cell counts of EGFP ${ }^{+}$ cells in PV+/+EGFP mice revealed the number of positive cells to be nearly identical to either $\mathrm{PV}^{+}$or $\mathrm{VVA}^{+}$cell numbers in the three ROIs, i.e., mPFC, SSC and striatum (Table 3). This indicates that the number of $\mathrm{VVA}^{+}$cells represents a reliable estimate of the Pvalb cells.
We then determined the number of cells positive for both PV and VVA in PV+/+ and PV $+/$ - mice. The percentage of double-labeled cells was rather homogeneous among brain regions and in the order of $70 \%$ in $\mathrm{PV}+/+$ and $55 \%$ in $\mathrm{PV}+/$ - brains (Fig. 3a, middle). The difference between genotypes was significant in all ROIs. For this calculation in $\mathrm{PV}+/+$ mice, we used the average of the $\mathrm{PV}^{+}$and $\mathrm{VVA}^{+}$cells, reckoning that this number represented the "real" number of Pvalb neurons; the use of $\mathrm{PV}^{+}$cell number only would not have significantly changed the results presented in Fig. 3a (not shown). Although PNNs enwrap mostly $\mathrm{PV}^{+}$neurons $[69,71]$, this overlap is not absolute. Hence, we first calculated the percentage of $\mathrm{PV}^{+}$cells that are surrounded by $\mathrm{VVA}^{+}$ PNNs. This percentage was found to be $\sim 75 \%$ in all the ROIs and there were no significant differences between $\mathrm{PV}+/+$ and $\mathrm{PV}+/$ - mice (Fig. 3a, right). Vice versa, $\mathrm{VVA}^{+}$ cells that also showed PV staining accounted for around $68 \%$ in PV $+/+$ mice for all the three ROIs. Values were clearly lower in $\mathrm{PV}+/$ - mice, on average $45 \%$, i.e., approximately one third fewer double-labeled cells compared to WT (Fig. 3a, right). This indicates that all identified $\mathrm{PV}^{+}$cells were highly likely to show VVA staining, while in a fraction of $\mathrm{VVA}^{+}$cells, $\mathrm{PV}$ expression levels, more prominently in $\mathrm{PV}+/$ - mice were below the predefined PV expression threshold and were thus not considered as double-labeled cells. PV protein levels in the forebrain of PND25 PV+/- mice were reduced by approximately $50 \%$ determined by semi-quantitative Western blot analyses (Fig. 3b), in line with previous findings in PV+/- adult mice [57]. No Western blot signal for PV was observed in samples from PV-/- mice as shown before $[49,57]$. For the normalization of the PV signals either CB or GAPDH bands were used (Fig. 3b) and results were not different when using either protein for the normalization. Pvalb mRNA levels were decreased to a similar extent $(\approx 50 \%)$ indicative of a regulation at the transcriptional level (Fig. 3c).

\section{PV expression levels are reduced in two canonical ASD models, Shank1-/- and Shank3B-/-, while VVA ${ }^{+}$Pvalb neuron numbers are unaltered}

As already reported in several studies [47, 72-74] canonical ASD mouse models were shown to display a reduction in the number of PV-immunoreactive cells in various brain regions. In most studies this was assumed to result from a cell loss of the $\mathrm{PV}^{+}$subpopulation. $\mathrm{Al}$ though ASD-linked gene defects/mutations were found to be of rather non-homogeneous origin, including proteins implicated in synaptic transmission, neurodevelopment, transcriptional regulation, etc., the morphological brain alterations observed in 26 ASD mouse models allowed a grouping into 3 major subgroups [75]. Knockout mice in group 1 including null mutants for En2, 


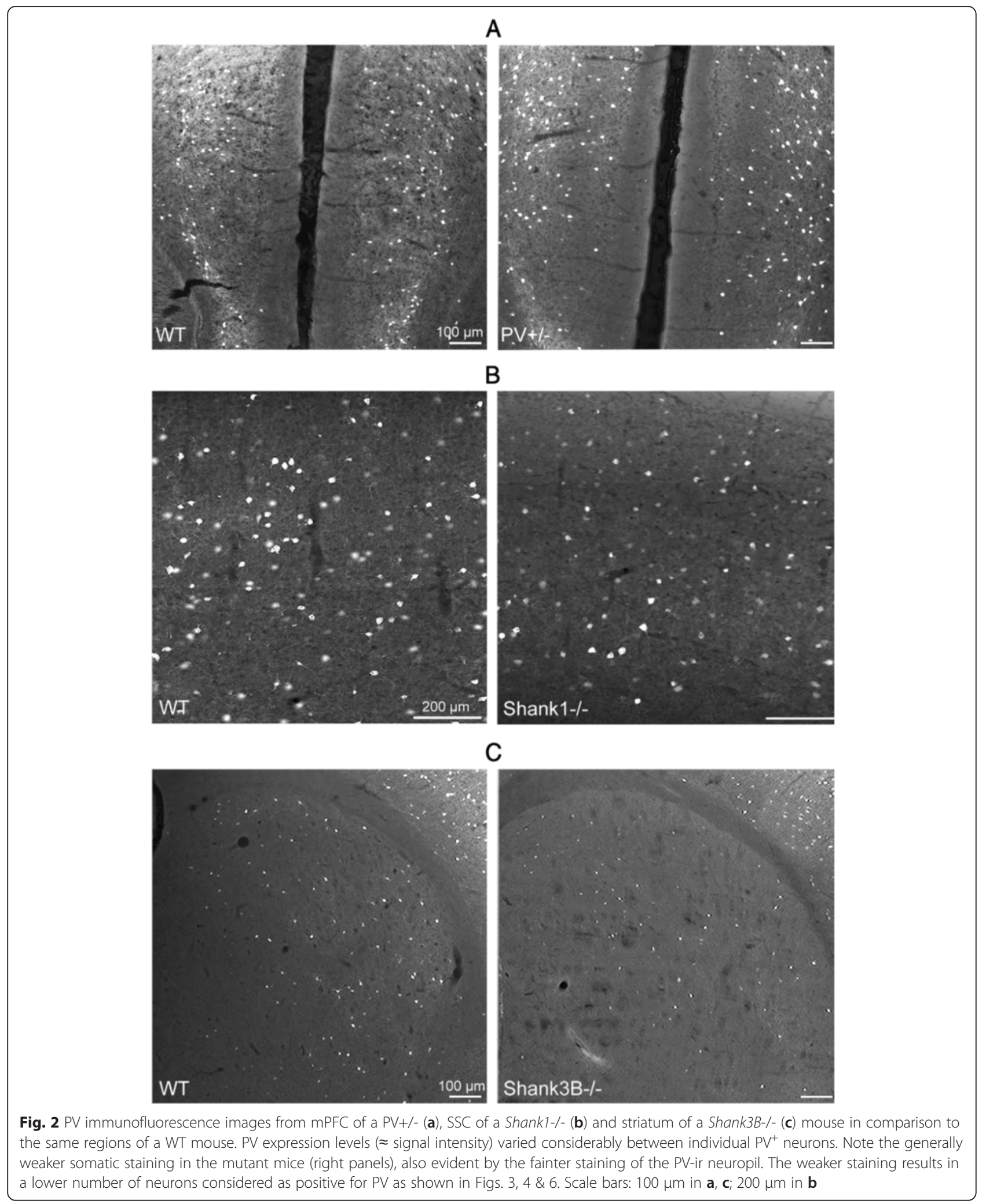

Fmr1 and Shank3 show an increase in the frontal and parieto-temporal lobes and a volume decrease in the cerebellum, as well as a decrease in PV staining. Similar neuroanatomical changes are present in PV-/- (Pvalb) mice, i.e., a transient cortical hypertrophy and a decrease in cerebellar volume at young age [48], indicating that 


\section{A}

medial Prefrontal Cortex (mPFC)
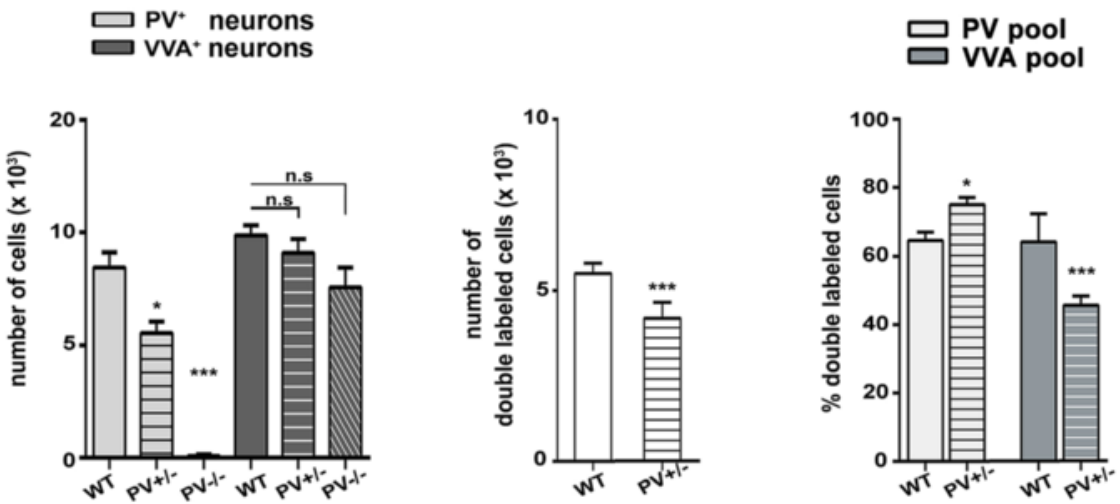

Somato-sensory cortex (SSC)
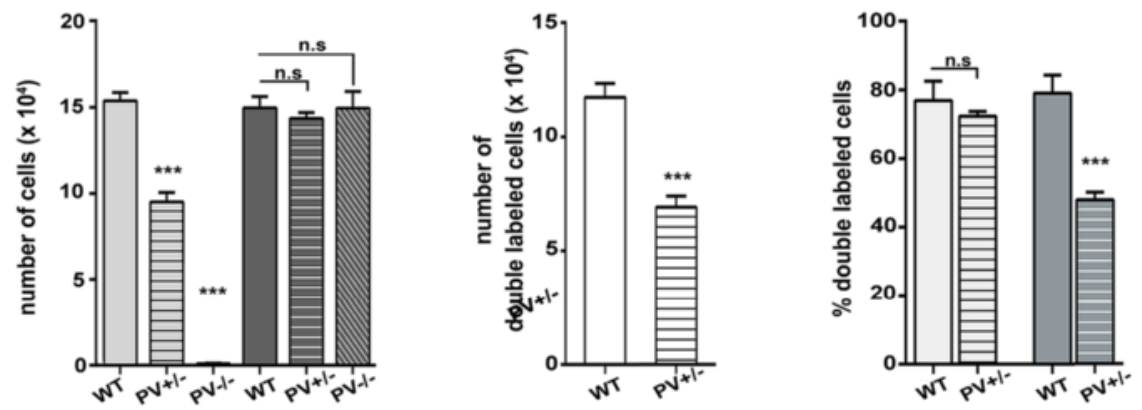

Striatum
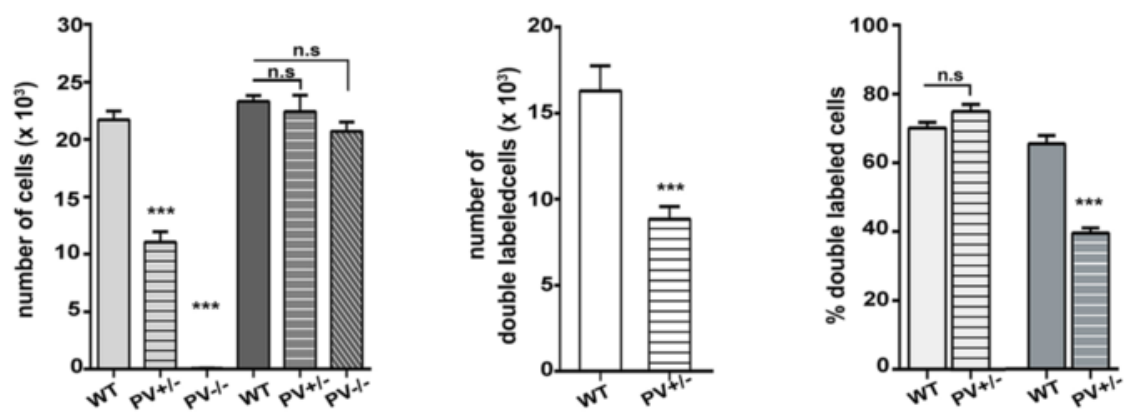

B

C
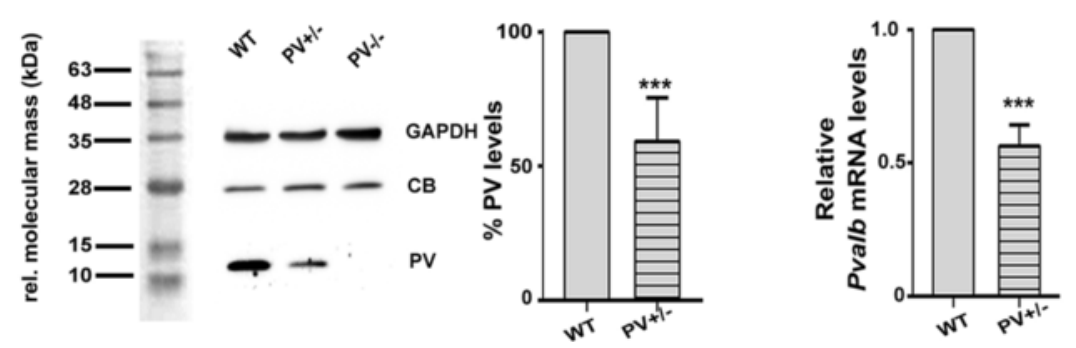

Fig. 3 (See legend on next page.) 
(See figure on previous page.)

Fig. 3 a Left: Stereological estimations of $\mathrm{PV}^{+}$(light gray) and WA (dark gray) cells in MPFC (upper row), SSC (middle row) and striatum (lower row) of PND25 WT, PV+/- and PV-/- male mice. Significant differences are observed in PV+ cells between WT, PV+/- and PV-/- animals $(p$-value $<0.05)$.

${ }^{*}$ Significant vs. WT mice. Asterisks represent ${ }^{*} P \leq 0.05,{ }^{* *} P \leq 0.01,{ }^{* *} P \leq 0.001$, respectively. Middle: stereological estimation of double-labeled (PV ${ }^{+} W A$ $\left.{ }^{+}\right)$cells of PND25 WT and PV+/- mice (white bars); Right: percentage of PV+ cells surrounded by WA (light gray) and WA ${ }^{+}$cells showing PV expression (dark gray) in WT and PV+/- mice. b Quantitative Western blot analysis of forebrain samples of P25 WT PV+/- and PV-/- mice. A representative Western blot (left) and the quantification of PV protein levels in WT and PV+/- forebrain are shown (right). No PV signal was detectable in PV-/- mice. The

Ponceau Red-stained protein markers loaded on the same membrane as the brain extract samples are shown with their respective molecular mass on the left. Data are from three independent experiments and are shown as mean \pm SEM. Results are expressed as a percentage of normalized PV levels measured in control (WT), defined as $100 \%$. GAPDH or calbindin D-28k (CB) signals served as loading controls and were used for the normalization of the PV signals. Both, CB and GAPDH expression levels were unchanged in PV+/- and Shank mutants compared to WT mice (data not shown). c qRTPCR values from P25 PV+/- mice representing Pvalb mRNA levels were normalized to $185 \mathrm{mRNA}$ levels and expressed as fold change compared to WT. Data from three independent experiments were pooled together and are shown as mean \pm SD. In all graphs, asterisks indicate statistical significance vs. WT ( $p$-value $<0.05, p=0.0003$ )

PV-/- likely belongs to the group 1 ASD models. Thus we extended our studies to two well-established genetic mouse models for ASD, namely Shank1-/- and Shank3B-/- mice. The two models display behavioral phenotypes with relevance to all core symptoms of ASD in humans [38-40] and cover the extremes of the spectrum with a gradient in severity in mental retardation [9]. Global PV expression levels as well as the ones in $\mathrm{PV}^{+}$neurons in various brain regions are currently unknown in these two mouse mutants; a decrease in PV staining intensity and puncta density of PV-ir neurons contacting pyramidal cells in the mouse insular cortex has been reported in Shank3B-/- mice [76].

Since expression patterns of the two proteins are quite different, i.e., high mRNA levels of Shank1 in cortex and hippocampus and of Shank3 in striatum and cortex [36, 77] (see also mouse Allen Brain atlas), we hypothesized to find the largest differences in PV expression in regions with high expression of the two Shank members. Thus, SSC and striatum were analyzed for Shank1-/- and Shank3B-/- mice, respectively. The number of $\mathrm{PV}^{+}$and $\mathrm{VVA}^{+}$cells was estimated as for the PV null-mutant mice by the optical fractionator method using the same counting criteria.

Results in the SSC of Shank1-/- mice were highly similar to the ones observed in the SSC of PV+/- mice. The number of $\mathrm{PV}^{+}$cells was significantly reduced to $62 \%$ of $\mathrm{PV}+/+$ in Shank1-/- mice, while the number of $\mathrm{VVA}^{+}$ cells was unaltered (Fig. 4a, left \& Table 4); representative PV immunofluorescence images of SSC from a WT

Table 3 Mean total number of $\mathrm{PV}^{+}$and $\mathrm{WA}^{+}$cells in the mPFC, SSC and striatum of PV $+/+, \mathrm{PV}+/-, \mathrm{PV}-/-$, as well as in PV+/+EGFP reporter mice

\begin{tabular}{|c|c|c|c|c|c|c|}
\hline & \multicolumn{3}{|c|}{$\mathrm{mPFC} \mathrm{PV}^{+}$} & \multicolumn{3}{|c|}{$\mathrm{mPFC} \mathrm{WA}^{+}$} \\
\hline & Mean & Range & $p$-value & Mean & Range & $p$-value \\
\hline $\mathrm{PV}+/+$ & 8908 & $7606-10,417$ & & 9292 & $6921-10,987$ & \\
\hline $\mathrm{PV}+/-$ & 5541 & $4321-7194$ & 0.0003 & 9015 & $7901-10,627$ & 0.3429 \\
\hline PV-/- & - & - & $<0.0001$ & 7421 & $5343-10,589$ & 0.0503 \\
\hline \multirow[t]{3}{*}{ PV+/+ EGFP } & 8732 & 6915-9713 & 0.7861 & 8664 & $7202-10,093$ & 0.1079 \\
\hline & \multicolumn{3}{|c|}{$\mathrm{SSC} \mathrm{PV}{ }^{+}$} & \multicolumn{3}{|c|}{$\mathrm{SSC} \mathrm{WA} \mathrm{W}^{+}$} \\
\hline & Mean & Range & $p$-value & Mean & Range & $p$-value \\
\hline $\mathrm{PV}+/+$ & 153729 & $144,549-166,441$ & & 149709 & $129,498-169,086$ & \\
\hline$P V+/-$ & 95157 & $82,476-109,745$ & $<0.0001$ & 143609 & $137,087-154,975$ & 0.4419 \\
\hline \multirow[t]{3}{*}{ PV-/- } & - & - & $<0.0001$ & 149594 & $120,020-174,596$ & 0.9925 \\
\hline & \multicolumn{3}{|c|}{ striatum $\mathrm{PV}^{+}$} & \multicolumn{3}{|c|}{ striatum $\mathrm{WA}^{+}$} \\
\hline & Mean & Range & $p$-value & Mean & Range & $p$-value \\
\hline $\mathrm{PV}+/+$ & 23332 & $22,384-25,012$ & & 21724 & $20,003-24,431$ & \\
\hline$P V+/-$ & 11036 & $8330-13,501$ & $<0.0001$ & 22445 & $17,158-24,801$ & 0.6613 \\
\hline PV-/- & - & - & $<0.0001$ & 20713 & $17,682-22,348$ & 0.3875 \\
\hline $\mathrm{PV}+/+\mathrm{EGFP}$ & 18562 & $17,670-19,681$ & $<0.0001$ & 19881 & $18,158-21,118$ & 0.0875 \\
\hline
\end{tabular}




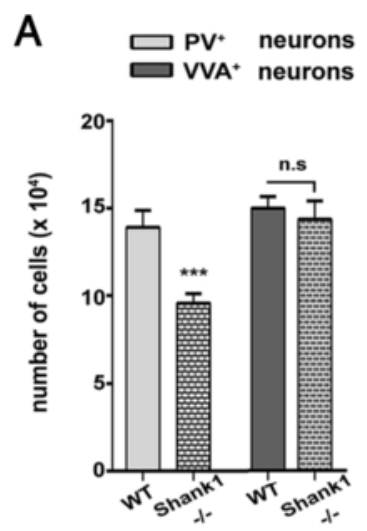

\section{Somato-sensory cortex (SSC)}
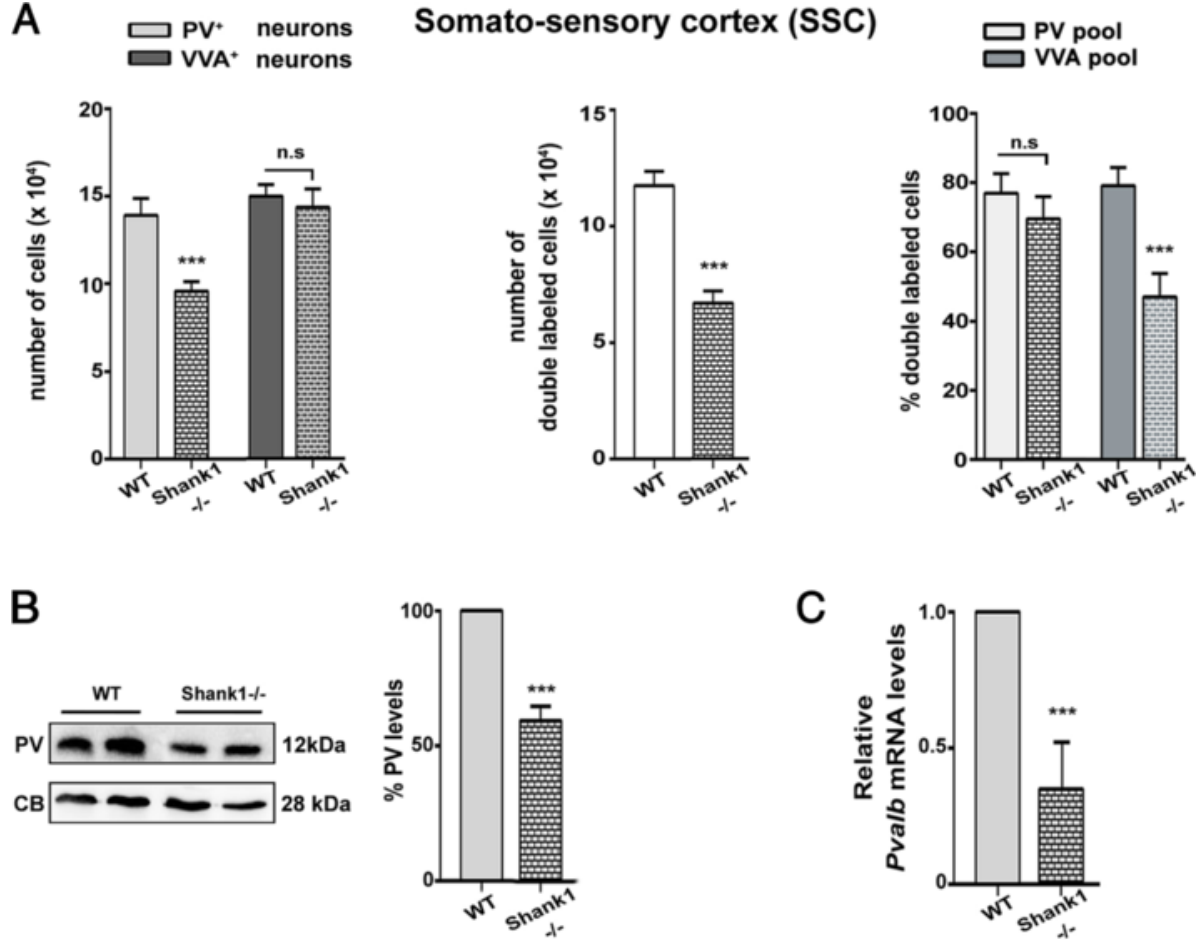

Fig. 4 a Left: stereological estimations of $\mathrm{PV}^{+}$(light gray) and WA+ (dark gray) cells in SSC of WT and Shank1-/- PND25 male mice. Middle: estimation of double-labeled cells in SSC of PND25 WT and Shank1-/- mice. Right: percentage of PV ${ }^{+}$cells surrounded by WA (light gray) and percentage of WA+ cells displaying PV expression and thus identified as PV+ cells (dark grey) in WT and Shank1-/- mice. b Representative Western blot and quantification of PV protein levels in Shank1-/- mice. CB signals were used as loading controls and served for the normalization of the PV signals. Data are from three independent experiments and are shown as mean \pm SEM. Results are expressed as percentage of normalized PV levels measured in control (WT) samples, defined as $100 \%$. c Quantitative RT-PCR analysis of forebrain samples of Shank1-/- mice. PV (Pvalb) mRNA levels were normalized to $18 \mathrm{~S} \mathrm{mRNA}$ levels and expressed as fold change. Data from three independent experiments were pooled together and are shown as mean \pm SD. In all graphs, asterisks indicate statistical significance vs. WT ( $p$-value $<0.05, p=0.0006$ )

and a Shank1-/- mouse are depicted in Fig. 2b. The lower PV levels not only led to weaker somatic PV signals, but also the staining intensity of the PV-positive neuropil was clearly reduced. Also results from the colocalization experiments (Fig. 4a, middle \& right) are essentially identical to the ones of $\mathrm{PV}+/$ - strongly indicative of $\mathrm{PV}$ down-regulation and not $\mathrm{PV}^{+}$cell loss. In support, quantitative RT-PCR results and moreover Western blots showed that both PV mRNA level and protein levels, respectively (Fig. 4b, c), were significantly decreased, demonstrating that the PV down-regulation occurs at the transcriptional level. As we expected to detect the largest differences in PV expression levels in brain regions with high Shank1 expression, as a control we also investigated PV expression in the striatum, a region with low Shank1 expression levels evidenced by ISH [36]. Qualitatively, immunofluorescence images revealed no prominent differences with respect to staining

Table 4 Mean total number of $\mathrm{PV}^{+}$and $\mathrm{WA}^{+}$cells in the SSC of Shank1-/- and in the striatum of Shank3B-/- mice in comparison to WT $(\mathrm{PV}+/+)$ mice in the two ROls

\begin{tabular}{|c|c|c|c|c|c|c|}
\hline & \multicolumn{3}{|l|}{$\mathrm{SSC} \mathrm{PV}$} & \multicolumn{3}{|c|}{$\mathrm{SSC} \mathrm{WA}^{+}$} \\
\hline & Mean & Range & $p$-value & Mean & Range & $p$-value \\
\hline $\mathrm{PV}+/+$ & 153729 & $144,549-166,441$ & & 149709 & $129,498-169,086$ & \\
\hline \multirow[t]{3}{*}{ Shank1-/- } & 96000 & $85,803-114,459$ & $<0.0001$ & 143392 & $128,601-166,705$ & 0.6250 \\
\hline & \multicolumn{3}{|c|}{ striatum $\mathrm{PV}^{+}$} & \multicolumn{3}{|c|}{ Striatum $W^{+}$} \\
\hline & Mean & Range & $p$-value & Mean & Range & $p$-value \\
\hline $\mathrm{PV}+/+$ & 23332 & $22,384-25,012$ & & 21724 & $20,003-24,431$ & \\
\hline Shank3B-/- & 12881 & $10,132-14,808$ & $<0.0001$ & 19951 & $16,887-22,811$ & 0.1910 \\
\hline
\end{tabular}


intensity and $\mathrm{PV}^{+}$neuron density between $\mathrm{WT}$ and Shank1-/- mice in the striatum (Fig. 5).

For the Shank3B-/- mice we focused on the striatum, a region with high Shank3 expression levels, as well as containing the subpopulation of PV-FSI, whose function were previously shown to be altered in the absence of PV [53]. While the number of $\mathrm{VVA}^{+}$cells was unchanged, the number of $\mathrm{PV}^{+}$cells was reduced to approximately $58 \%$ (Fig. 6a, left \& Table 4). The decrease was clearly visible on immunofluorescence images of the striatum of a Shank3B-/- mouse in comparison to a WT animal (Fig. 2c). The co-localization studies also revealed a decrease of double-labeled cells, again mostly resulting from a reduction in $\mathrm{PV}^{+}$cells showing VVA staining (Fig. 6a, middle). Interestingly, in the Shank3B-/- mice, the number of $\mathrm{PV}^{+}$cells also expressing VVA was even slightly increased (Fig. 6a, right). However, counting and co-localization results show globally similar results as for PV+/- and Shank1-/- mice, i.e., a reduction of PV expression in the unchanged number of striatal $\mathrm{VVA}^{+}$ cells. Both RT-PCR and Western blot analysis revealed the PV mRNA and protein expression levels to be significantly lower, i.e., to $53 \pm 8$ and $50 \pm 9 \%$ of $\mathrm{PV}+/+$ levels for mRNA and protein, respectively (Fig. 7b, c). Based on the rather low Shank3 ISH signals in the cortex and the hippocampus, we hypothesized to observe minor (if any) effects on PV expression in these brain regions. Qualitatively, immunofluorescence images of cortex (Fig. 7a, b) and hippocampus (Fig. 7c, d) revealed no obvious differences between WT (a, c) and Shank3B-/(b, d) mice. Quantitatively, the PV Western blot signals
(Fig. 7e) were not significantly different between genotypes $(100 \pm 15 \%$ in WT vs. $103 \pm 25 \%$; in Shank3B-/-; mean \pm S.D., $n=5$ mice per genotype; $p=0.78$ ).

Thus, in both Shank knockout ASD models, PV protein expression levels were decreased in those brain regions normally expressing high levels of either Shank1 or Shank3 in WT mice likely arising from alterations at the transcriptional level, in view of the similar decrease in Pvalb mRNA. Importantly, in all three ASD models there was no evidence for a Pvalb neuron loss.

\section{Discussion}

One of the difficulties in gaining knowledge on the mechanisms underlying the pathogenesis of ASD is the large number $(>100)$ of putative ASD risk genes identified in genetic studies in humans and animal models $[4,78,79]$. An important line of evidence has centered on mutations in genes implicated in synapse structure and/or function including NRXN, NLGN and SHANK family members $[17-19,80]$. Such mutations might eventually lead to an alteration of the E/I balance as demonstrated in some ASD mouse models $[7,8]$. Other hypotheses on ASD-associated genes and/or gene/environment relationships come from many computational studies (GWAS, transcriptomic expression network analyses); several ones revealed impaired $\mathrm{Ca}^{2+}$ signaling, i.e., alterations in the $\mathrm{Ca}^{2+}$ node in gene networks $[4,81,82]$ to represent a convergence of mechanisms relating to ASD, in line with previous propositions [83-85]. PV plays an important role in the $\mathrm{Ca}^{2+}$ homeostasis regulating many

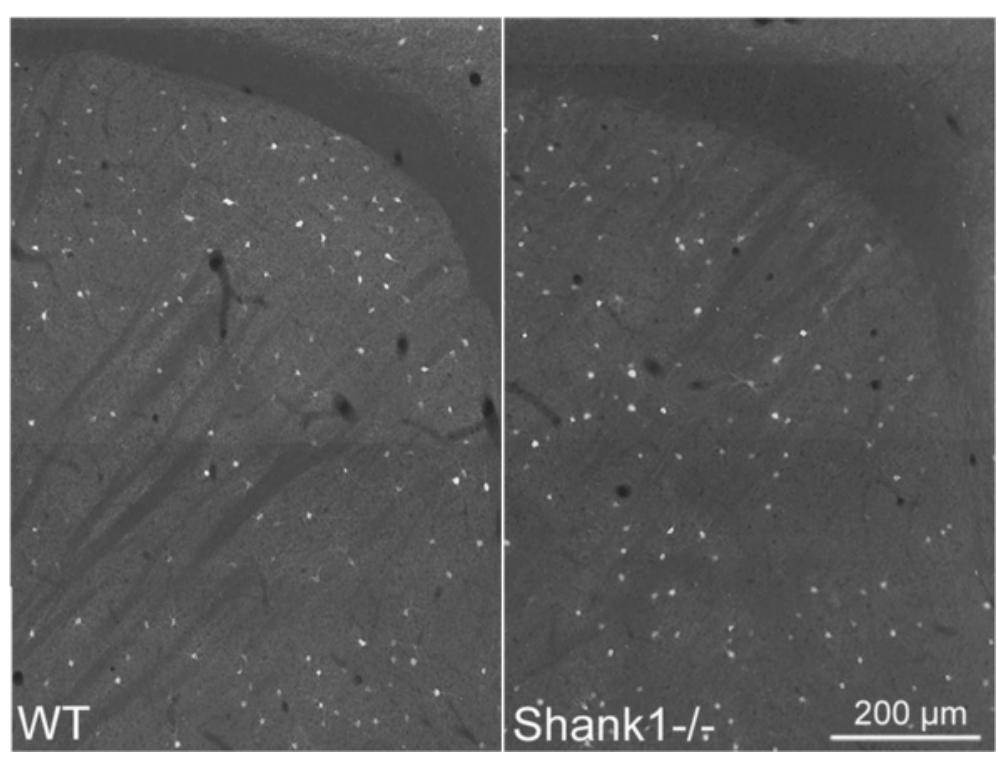

Fig. 5 Representative PV immunofluorescence images from the striatum of a WT and a Shank1-/- mouse. No qualitative differences in the number and signal intensities of $\mathrm{PV}^{+}$neurons were observed between genotypes. Scale bar: $200 \mu \mathrm{m}$ 
A
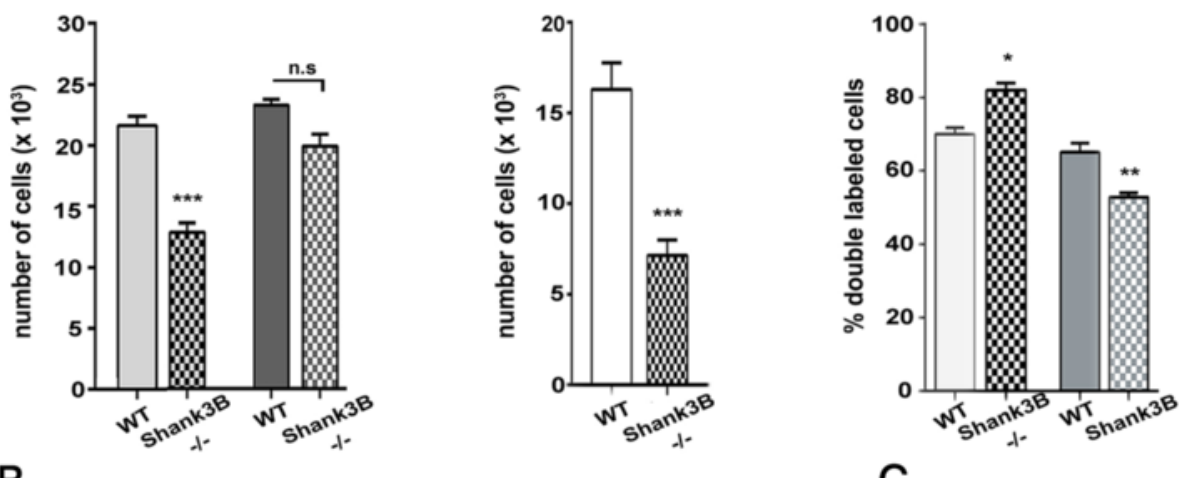

B

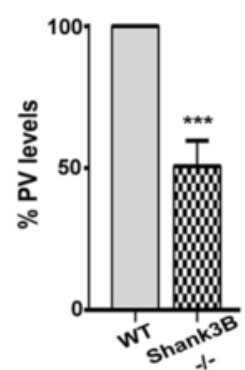

C

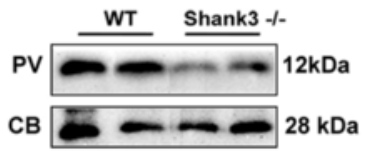

Fig. 6 a) Left: stereological estimations of $\mathrm{PV}^{+}$(light gray) and WA+ (dark gray) cells in the striatum of WT and Shank3B-/- PND25 male mice. Middle: estimation of double-labeled cells in SSC of PND25 WT and Shank3B-/- mice. Right: percentage of PV ${ }^{+}$cells surrounded by WA (light gray) and $\mathrm{WA}^{+}$cells with PV expression (dark grey) in WT and Shank3B-/- mice. b) Representative Western blot and quantification of PV protein levels in Shank3B-/- mice. CB was used as loading control for the normalization of the PV signal, since CB expression levels were unchanged in Shank3B-/- mice (data not shown). Data are from three independent experiments and are shown as mean \pm SEM. Results are expressed as a percentage of normalized PV levels measured in control (WT), defined as $100 \%$. c) Quantitative RT-PCR analysis of forebrain samples of Shank3B-/mice. PV (Pvalb) mRNA levels were normalized to $185 \mathrm{mRNA}$ levels and expressed as fold change. Data from three independent experiments were pooled together and are shown as mean \pm SD. In all graphs, asterisks indicate statistical significance vs. WT ( $p$-value $<0.05, p=0.0002$ )

aspects of neuronal signaling (short-term plasticity, synchronization, precision of spike timing, etc.) in the subpopulation of $\mathrm{PV}^{+}$interneurons [56]. Absence/ down-regulation of $\mathrm{PV}$ in $\mathrm{PV}-/-$ and $\mathrm{PV}+/$ - mice, respectively, not only affects the properties of the Pvalb neurons, but also of neurons impacting on Pvalb cells, and leads to a robust ASD-like behavioral phenotype characterized by impaired social interaction behavior, reduced pro-social ultrasonic vocalizations and deficits in reversal learning [48]. Of relevance, a decrease in the number of $\mathrm{PV}^{+}$cells has been reported in many genetic ASD mouse models in various brain regions including mPFC, SSC and striatum; (see Table S1 in [48]). Also in the few human studies, a decrease in $\mathrm{PV}^{+}$cells and/or PVALB mRNA was reported $[46,86]$. Thus, the networks containing Pvalb neurons were hypothesized to be strongly implicated in ASD [45].
While an involvement of Pvalb neurons in ASD is rather undisputed, it remains unclear whether the observed reduction of $\mathrm{PV}^{+}$cells in a particular brain region is the result of I) a truly decreased number of Pvalb neurons resulting from the many putative mechanisms including an immature or perturbed developmental state (e.g., layer- and/or region-inappropriate localization of Pvalb neurons, increased susceptibility, premature cell death, etc.) or II) alternatively from the down-regulation of PV protein levels or the failure to express adequate levels of the protein. To address this question, one needs to identify Pvalb cells by another means; one of the most common marker is the particular extracellular matrix surrounding Pvalb cells that can be visualized by VVA staining. Of note, the appearance of VVA staining is developmentally and layer-dependent regulated as shown in the mouse visual cortex (V1) [87] and the barrel 

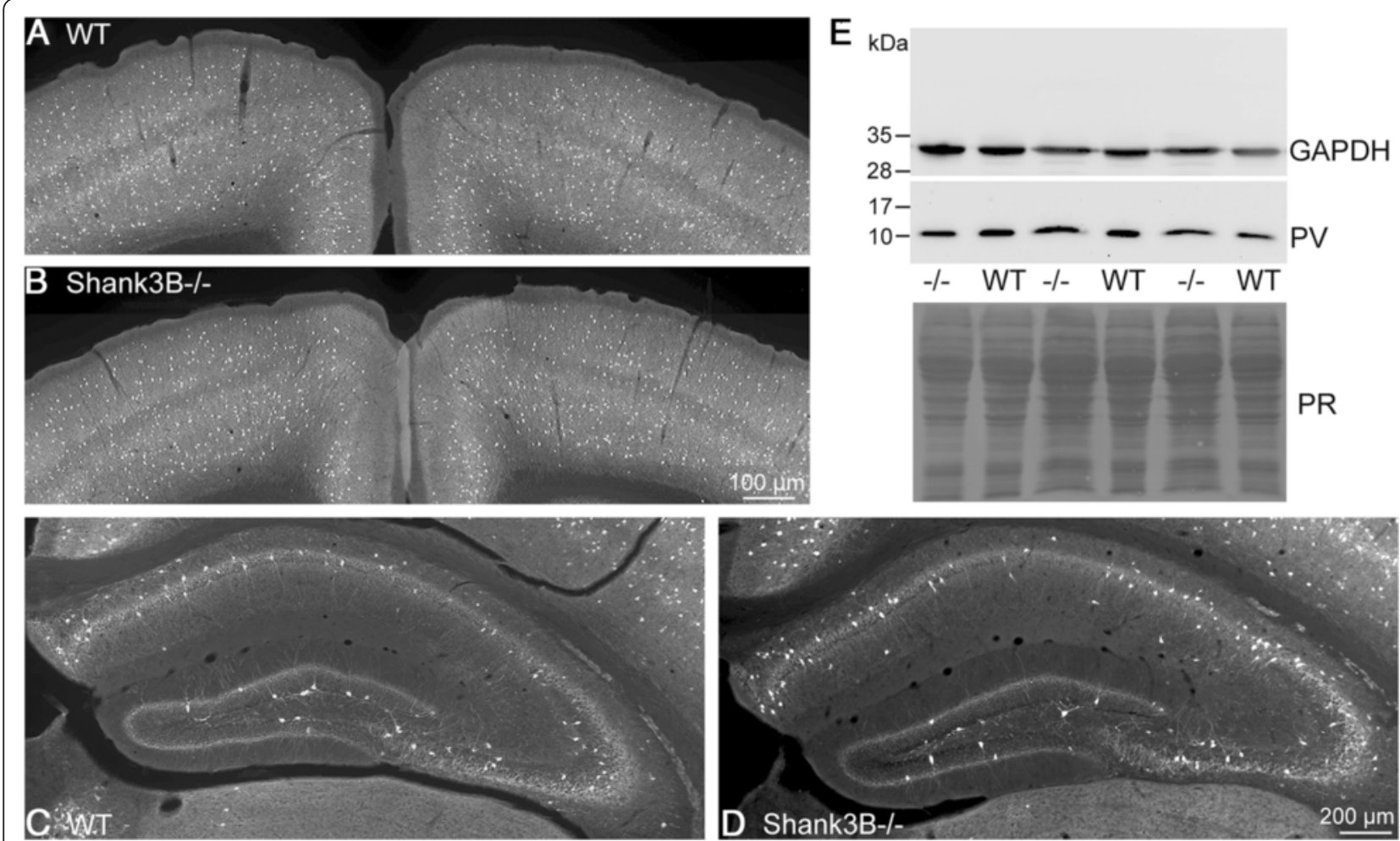

Fig. 7 Representative PV immunofluorescence images (a-d) and Western blot analyses (e) from cortex and hippocampus of WT (a, c) and Shank3B-/- (b, d) mice. No apparent differences in the number or signal intensity of $\mathrm{PV}^{+}$neurons in both brain regions were evident between $\mathrm{WT}^{-}$ and Shank3B-/- mice. Scale bars in a and b: $100 \mu \mathrm{m}$; in c and d: $200 \mu \mathrm{m}$. e) Western blot signals from brain homogenates containing cortex and hippocampus showed relatively high signal variability independent of the genotype. For the normalization of the PV signal either the GAPDH Western blot signal (upper part) or the intensity of the Ponceau Red-stained membrane (PR) was used. Results from 3 WT and 3 Shank3B-/-mice are depicted. The positions of the molecular weight markers are indicated. Due to the large difference in signal intensities for GAPDH and PV, the membrane was cut and exposed individually

cortex [88]. Moreover, PNNs are regulated by activity and are decreased under certain pathological conditions such as oxidative stress [89] or Alzheimer's disease [90]. Thus, in the first step we ascertained by stereology [60] that the number of $\mathrm{VVA}^{+}$cells was unchanged in mice with reduced $(\mathrm{PV}+/-)$ or absent $(\mathrm{PV}-/-) \mathrm{PV}$ expression in the mPFC, SSC and striatum. In agreement with previous results obtained in the cortex and hippocampus of adult PV-/- mice [55, 57], there was no indication of a cell decrease/loss of Pvalb neurons. Moreover, in a mouse line expressing EGFP in Pvalb neurons, the number of $\mathrm{EGFP}^{+}$cells was found to be the same as for $\mathrm{PV}^{+}$and $\mathrm{VVA}^{+}$cells in $\mathrm{PV}+/+$ mice indicative of the identification of the essentially same Pvalb cell population, where either morphological or functional abnormalities have been reported in ASD [91-93]. Analyses of double-labeled $\left(\mathrm{VVA}^{+}\right.$and $\left.\mathrm{PV}^{+}\right)$cells using either the total of $\mathrm{PV}^{+}$or $\mathrm{VVA}^{+}$cells for normalization revealed approximately $70-80 \%$ of co-stained cells within the mPFC, SSC and striatum of WT mice. Similar numbers were reported in the mouse cortical V1 region, where
$82 \%$ of all VVA ${ }^{+}$cells were found to also express PV [87]. While the percentage of $\mathrm{PV}^{+}$cells enwrapped by PNN $\left(\mathrm{VVA}^{+}\right)$was not different between sections from WT and $\mathrm{PV}+/$ - mice, as the result of decreased PV protein expression levels in $\mathrm{PV}+/-$ mice, both the total number of $\mathrm{PV}^{+}$ cells, as well as the percentage of $\mathrm{VVA}^{+}$cells expressing PV was significantly decreased in all regions analyzed in our study.

Thus, we wondered, whether the previously reported decrease in $\mathrm{PV}^{+}$cells in other canonical ASD mouse models might not be -globally or in part- the result of PV down-regulation. We therefore assessed PV protein expression and VVA as a marker for Pvalb cells in the Shank1 and Shank3 mouse models. The selection among the many ASD mouse models available was based on the fact that more than 900 patients with genetic alterations in SHANK genes were identified, with the SHANK gene family being the primary gene family implicated in ASD [9]. Shank1 and Shank3 mouse models were selected to cover both extremes of the spectrum, namely SHANK1 mutations found in individuals with ASD and normal 
intelligence and SHANK3 mutations associated with severe mental retardation [9]. The selection was further facilitated by a recent comprehensive neuro-morphological MRI study on 26 ASD mouse models [75]. Similar to the most consistent finding in humans [94, 95], an increase in the frontal and parieto-temporal lobes and decreased volume of the cerebellar cortex were observed in one of the three subgroups ("group 1") identified among the 26 investigated models [75]. A prominent example of the "group 1" ASD mouse models are Shank3 null mutant mice. Importantly, however, also the morphological changes in PV-/- mice follow the same pattern, as we recently demonstrated: increased neocortical volume and a decreased size of the cerebellum [48]. A further link exists between Shank protein expression and Pvalb neurons $[76,96]$. In Shank1-/- hippocampal PV ${ }^{+}$FSI the absence of Shank1 functionally leads to a decrease in excitatory synaptic inputs and inhibitory synaptic outputs to pyramidal neurons and furthermore to molecular changes including the down-regulation of the postsynaptic proteins GKAP, PSD-95 and gephyrin [96]. These alterations affect the E/I balance in CA1 pyramidal neurons. Whether a similar situation prevails in Shank1-/- cortical $\mathrm{PV}^{+}$FSI is currently unknown. In Shank3 knockout mice, a reduction in $\mathrm{PV}^{+}$puncta staining (intensity and puncta numbers) around pyramidal cells in the insular cortex of Shank3B-/mice was associated with weakened GABAergic circuit function and impaired postnatal pruning [76]. Moreover, the decrease in PV-ir puncta intensity in Shank3B-/hinted towards a PV expression-related phenomenon, although the question of PV expression levels was not directly addressed in this study.

For the Shank models our interest was focused on regions with high expression of either protein, i.e., SSC for Shank1-/- and striatum for Shank3B-/-. In both ASD models, the $\mathrm{VVA}^{+}$cell number was unchanged and the number of $\mathrm{PV}^{+}$cells was decreased, also evidenced by the decreased percentage of $\mathrm{PV}^{+}$cells among all $\mathrm{VVA}^{+}$cells. A decrease in PV protein levels and Pvalb mRNA levels to approximately $50 \%$ of WT in both Shank mutants are in full support of a down-regulation of PV. In addition, the demonstration that PV levels are decreased may indicate a shift in the E/I balance towards an increased inhibition, taking into account the proven role of PV in synaptic transmission $[52,53,55,97,98]$. In striatal $\mathrm{PV}^{+}$ FSI the increased facilitation (increased inhibition) between FSI and medium spiny neurons (MSN) caused by the absence of PV in PV-/-mice [53] is partly compensated by a decrease in the excitatory synaptic input from cortical pyramidal cells, a mechanism hypothesized to compensate for the increased output of PV-/- neurons [48]. The modification of the E/I balance within the PV-circuitry in PV-/mice is reminiscent of the situation in schizophrenia, where NMDA receptor hypofunction leads to the reduction of glutamic acid decarboxylase 67 (GAD67) levels and thus GABA synthesis. The concomitant decrease in PV expression levels might be viewed as an adaptive/compensatory response in order to enhance facilitation (inhibition) and to compensate -at least partially- for the decrease in GAD67 [99-101].

How might the absence of either Shank proteins lead to PV down-regulation? The similar magnitude in downregulation of PV and Pvalb mRNA in both Shank mutants is indicative of a regulation at the transcriptional level. Currently little is known on the physiological regulation of PV expression in the brain. The enfeebled GABAergic circuit function reported in Shank3B-/- [76] and Shank1-/mice [96] is likely to decrease somatic $\mathrm{Ca}^{2+}$ signals and subsequently modify the $\mathrm{Ca}^{2+}$ signaling components of Pvalb neurons; a neuronal activity-related $\mathrm{Ca}^{2+}$-dependent transcriptional regulation of PV expression was proposed before [100]. Thus, the impairment in GABAergic function reported in both Shank models is likely to impact on the $\mathrm{Ca}^{2+}$-dependent excitability-transcription $(\mathrm{E} / \mathrm{T})$ coupling including transcription of the Pvalb gene. Alterations in other genes implicated in $\mathrm{E} / \mathrm{T}$ coupling have been observed before in ASD individuals and include $\mathrm{Ca}^{2+}$ signaling components such as the voltage-dependent channels $\mathrm{Ca}_{\mathrm{v}} 1.2(C A C N A 1 C), \mathrm{Ca}_{\mathrm{v}} 1.3(C A C N A 1 D)$ and the $\alpha-\delta$ auxiliary subunit of L-type voltage-gated $\mathrm{Ca}^{2+}$ channels (CACNA2D3) [102, 103]. Evidence has accumulated that mutated ASD risk genes are critical components of activity-regulated signaling networks often controlling synapse development and morphology, as well as structural and functional plasticity [8]. In summary, the observed decrease in PV expression in Shank mutant mice might be viewed as an adaptive or compensatory mechanism to possibly restore (increase) synaptic output according to the concept of the $\mathrm{Ca}^{2+}$ homeostasome [104].

Our findings might have important implications for novel treatment strategies for ASD, particularly as most current strategies aim to enhance inhibition in order to compensate for a presumed increase in excitatory neurotransmission, e.g., by the $\mathrm{GABA}_{\mathrm{B}}$ receptor agonist barbaclofen $[80,105]$. Our findings indicate the exact opposite, namely that an enhancement of excitatory neurotransmission onto $\mathrm{PV}^{+}$neurons possibly restoring PV levels and thus PV-modulated functions (e.g., short-term plasticity, synchronization, precision of spike timing) may ameliorate ASD symptoms. Alternatively, one might envisage that direct up-regulation of PV might be a means to ameliorate PV-circuitry function resulting in the attenuation -or in the best case abolition- of the ASD phenotype.

\section{Conclusions}

Stereological analysis of Pvalb neurons in mice heterozygous and homozygous for a deletion of the functional Pvalb gene (PV+/- and PV-/- mice, respectively, both 
showing an ASD-like phenotype) revealed their numbers to be unaltered in comparison to WT mice. A similar situation as in $\mathrm{PV}+/$ - mice prevailed in the two ASD mouse models Shank1-/- and Shank3B-/-: the number of Pvalb neurons was unchanged in brain regions with high expression of either protein, while PV protein and Pvalb mRNA levels were decreased by approximately $50 \%$. Based on the similar magnitude in PV down-regulation and impairment in the E/I balance reported before in all three models we hypothesize that the PV system, in particular reduced PV expression levels, might represent a convergent downstream endpoint for some forms of ASD.

\section{Ethics approval and consent to participate}

All experiments were performed with permission of the local animal care committees (Canton of Fribourg, Switzerland; Regierungspräsidium Gießen, Germany) and according to the present Swiss/Germany law and the European Communities Council Directive of 24 November 1986 (86/609/EEC).

\section{Abbreviations}

ASD: autism spectrum disorders; CB: calbindin D-28k; CE: coefficient of error; EGFP: enhanced green fluorescent protein; FSI: fast-spiking interneurons; GAD67: glutamic acid decarboxylase 67; ISH: in situ hybridization; mPFC: medial prefrontal cortex; PND: postnatal day; PV: parvalbumin; SSC: somatosensory cortex; WA: vicia villosa agglutinin.

\section{Competing interests}

All authors declare that they have no competing interests.

\section{Authors' contributions}

BS conceived the study, participated in the data analyses and in the writing of the manuscript. FF carried out the Stereology experiments, performed the statistical analysis and participated in writing of the manuscript. KJV, AÖS and MW provided and characterized the Shank mutant mice. MW additionally participated in the design of the study and participated in the writing of the manuscript. All authors read and approved the final manuscript.

\section{Acknowledgements}

The authors wish to thank Simone Eichenberger and Martine Steinauer, University of Fribourg, for the maintenance of the mouse facility and technical assistance, respectively. We highly appreciate the help of Dr. Lutz Slomianka, University of Zurich, Switzerland for the support in the stereological analyses.

\section{Funding}

This study was supported by grants from the Swiss National Science Foundation (SNF grants: \#130680 and \#155952 to B.S.) and the Deutsche Forschungsgemeinschaft (DFG WO 1732/1-1 to M.W.).

\section{Author details}

${ }^{1}$ Anatomy, Department of Medicine, University of Fribourg, Route Albert-Gockel 1, CH-1700 Fribourg, Switzerland. 'Behavioral Neuroscience, Faculty of Psychology, Philipps-University of Marburg, Gutenbergstraße 18, D-35032 Marburg, Germany.

Received: 15 October 2015 Accepted: 20 January 2016

Published online: 27 January 2016

\section{References}

1. Centers for Disease Control and Prevention. Prevalence of autism spectrum disorder among children aged 8 years - autism and developmental disabilities monitoring network, 11 sites, United States, 2010. MMWR Surveill Summ. 2014;63(2):1-21.
2. Levitt P, Campbell DB. The genetic and neurobiologic compass points toward common signaling dysfunctions in autism spectrum disorders. J Clin Invest. 2009;119(4):747-54. doi:10.1172/JCI37934.

3. Zoghbi HY, Bear MF. Synaptic dysfunction in neurodevelopmental disorders associated with autism and intellectual disabilities. Cold Spring Harb Perspect Biol. 2012. doi:10.1101/cshperspect.a009886.

4. Abrahams BS, Geschwind DH. Advances in autism genetics: on the threshold of a new neurobiology. Nat Rev Genet. 2008;9(5):341-55. doi:10.1038/nrg2346.

5. Pardo CA, Eberhart CG. The neurobiology of autism. Brain Pathol. 2007;17(4): 434-47. doi:10.1111/j.1750-3639.2007.00102.x.

6. LeBlanc JJ, Fagiolini M. Autism: a "critical period" disorder? Neural Plast. 2011;2011:921680. doi:10.1155/2011/921680.

7. Rubenstein JL, Merzenich MM. Model of autism: increased ratio of excitation/inhibition in key neural systems. Genes Brain Behav. 2003;2(5): 255-67.

8. Ebert DH, Greenberg ME. Activity-dependent neuronal signalling and autism spectrum disorder. Nature. 2013;493(7432):327-37. doi:10.1038/nature11860.

9. Leblond CS, Nava C, Polge A, Gauthier J, Huquet G, Lumbroso S, et al. Metaanalysis of SHANK mutations in autism spectrum disorders: a gradient of severity in cognitive impairments. PLoS Genet. 2014;10(9), e1004580. doi:10. 1371/journal.pgen.1004580.

10. Kim E, Sheng M. PDZ domain proteins of synapses. Nat Rev Neurosci. 2004; 5(10):771-81. doi:10.1038/nrn1517.

11. Guilmatre A, Huguet $G$, Delorme R, Bourgeron $T$. The emerging role of SHANK genes in neuropsychiatric disorders. Dev Neurobiol. 2014;74(2):11322. doi:10.1002/dneu.22128.

12. Ting JT, Peca J, Feng G. Functional consequences of mutations in postsynaptic scaffolding proteins and relevance to psychiatric disorders. Annu Rev Neurosci. 2012:35:49-71. doi:10.1146/annurev-neuro-062111-150442.

13. Sato D, Lionel AC, Leblond CS, Prasad A, Pinto D, Walker S, et al. SHANK1 deletions in males with autism spectrum disorder. Am J Hum Genet. 2012; 90(5):879-87. doi:10.1016/j.ajhg.2012.03.017.

14. Berkel S, Marshall CR, Weiss B, Howe J, Roeth R, Moog U, et al. Mutations in the SHANK2 synaptic scaffolding gene in autism spectrum disorder and mental retardation. Nat Genet. 2010:42(6):489-91. doi:10.1038/ng.589.

15. Pinto D, Pagnamenta AT, Klei L, Anney R, Merico D, Regan R, et al. Functional impact of global rare copy number variation in autism spectrum disorders. Nature. 2010;466(7304):368-72. doi:10.1038/nature09146.

16. Leblond CS, Heinrich J, Delorme R, Proepper C, Betancur C, Huguet G, et al. Genetic and functional analyses of SHANK2 mutations suggest a multiple hit model of autism spectrum disorders. PLoS Genet. 2012;8(2), e1002521. doi:10.1371/journal.pgen.1002521.

17. Durand CM, Betancur C, Boeckers TM, Bockmann J, Chaste P, Fauchereau F, et al. Mutations in the gene encoding the synaptic scaffolding protein SHANK3 are associated with autism spectrum disorders. Nature Genet. 2007; 39(1):25-7. doi:10.1038/ng1933.

18. Sudhof TC. Neuroligins and neurexins link synaptic function to cognitive disease. Nature. 2008:455(7215):903-11. doi:10.1038/nature07456.

19. Won H, Lee HR, Gee HY, Mah W, Kim Jl, Lee J, et al. Autistic-like social behaviour in Shank2-mutant mice improved by restoring NMDA receptor function. Nature. 2012;486(7402):261-5. doi:10.1038/nature11208.

20. Gauthier J, Spiegelman D, Piton A, Lafreniere RG, Laurent S, St-Onge J, et al. Novel de novo SHANK3 mutation in autistic patients. Am J Med Genet B Neuropsychiatr Genet. 2009;150B(3):421-4. doi:10.1002/ajmg.b. 30822.

21. Moessner R, Marshall CR, Sutcliffe JS, Skaug J, Pinto D, Vincent J, et al. Contribution of SHANK3 mutations to autism spectrum disorder. Am J Hum Genet. 2007;81(6):1289-97. doi:10.1086/522590.

22. Bonaglia MC, Giorda R, Borgatti R, Felisari G, Gagliardi C, Selicorni A, et al. Disruption of the ProSAP2 gene in a $t(12 ; 22)(q 24.1 ; q 13.3)$ is associated with the 22q13.3 deletion syndrome. Am J Hum Genet. 2001;69(2):261-8. doi:10. 1086/321293.

23. Phelan MC, Rogers RC, Saul RA, Stapleton GA, Sweet K, McDermid H, et al. $22 q 13$ deletion syndrome. Am J Med Genet. 2001;101(2):91-9.

24. Wilson HL, Wong AC, Shaw SR, Tse WY, Stapleton GA, Phelan MC, et al. Molecular characterisation of the 22q13 deletion syndrome supports the role of haploinsufficiency of SHANK3/PROSAP2 in the major neurological symptoms. J Med Genet. 2003;40(8):575-84.

25. Manning MA, Cassidy SB, Clericuzio C, Cherry AM, Schwartz S, Hudgins $L$, et al. Terminal 22q deletion syndrome: a newly recognized cause of 
speech and language disability in the autism spectrum. Pediatrics. 2004; 114(2):451-7.

26. Phelan MC. Deletion 22q13.3 syndrome. Orphanet J Rare Dis. 2008;3:14. doi:10.1186/1750-1172-3-14.

27. Wohr M, Roullet Fl, Hung AY, Sheng M, Crawley JN. Communication impairments in mice lacking Shank1: reduced levels of ultrasonic vocalizations and scent marking behavior. PLoS One. 2011;6(6), e20631. doi: 10.1371/journal.pone.0020631.

28. Sungur AO, Vorckel KJ, Schwarting RK, Wohr M. Repetitive behaviors in the Shank1 knockout mouse model for autism spectrum disorder: developmental aspects and effects of social context. J Neurosci Methods. 2014;234:92-100. doi:10.1016/j.jneumeth.2014.05.003.

29. Hung AY, Futai K, Sala C, Valtschanoff JG, Ryu J, Woodworth MA, et al. Smaller dendritic spines, weaker synaptic transmission, but enhanced spatial learning in mice lacking Shank1. J Neurosci. 2008;28(7):1697-708. doi:10.1523/JNEUROSCI.3032-07.2008.

30. Silverman JL, Turner SM, Barkan CL, Tolu SS, Saxena R, Hung AY, et al. Sociability and motor functions in Shank1 mutant mice. Brain Res. 2011; 1380:120-37. doi:10.1016/j.brainres.2010.09.026.

31. Ey E, Torquet N, Le Sourd AM, Leblond CS, Boeckers TM, Faure P, et al. The Autism ProSAP1/Shank2 mouse model displays quantitative and structural abnormalities in ultrasonic vocalisations. Behav Brain Res. 2013;256:677-89. doi:10.1016/j.bbr.2013.08.031.

32. Schmeisser MJ, Ey E, Wegener S, Bockmann J, Stempel AV, Kuebler A, et al. Autistic-like behaviours and hyperactivity in mice lacking ProSAP1/Shank2. Nature. 2012;486(7402):256-60. doi:10.1038/nature11015.

33. Bozdagi O, Sakurai T, Papapetrou D, Wang X, Dickstein DL, Takahashi N, et al. Haploinsufficiency of the autism-associated Shank3 gene leads to deficits in synaptic function, social interaction, and social communication. Mol Autism. 2010;1(1):15. doi:10.1186/2040-2392-1-15.

34. Yang M, Bozdagi O, Scattoni ML, Wohr M, Roullet FI, Katz AM, et al. Reduced excitatory neurotransmission and mild autism-relevant phenotypes in adolescent Shank3 null mutant mice. J Neurosci. 2012;32(19):6525-41. doi:10.1523/JNEUROSCI.6107-11.2012.

35. Kouser M, Speed HE, Dewey CM, Reimers JM, Widman AJ, Gupta N, et al. Loss of predominant Shank3 isoforms results in hippocampus-dependent impairments in behavior and synaptic transmission. J Neurosci. 2013;33(47): 18448-68. doi:10.1523/JNEUROSCI.3017-13.2013.

36. Peca J, Feliciano C, Ting JT, Wang W, Wells MF, Venkatraman TN, et al. Shank3 mutant mice display autistic-like behaviours and striatal dysfunction. Nature. 2011;472(7344):437-42. doi:10.1038/nature09965.

37. Wang X, McCoy PA, Rodriguiz RM, Pan Y, Je HS, Roberts AC, et al. Synaptic dysfunction and abnormal behaviors in mice lacking major isoforms of Shank3. Hum Mol Genet. 2011;20(15):3093-108. doi:10.1093/hmg/ddr212.

38. Jiang $\mathrm{YH}$, Ehlers MD. Modeling autism by SHANK gene mutations in mice. Neuron. 2013;78(1):8-27. doi:10.1016/j.neuron.2013.03.016.

39. Herbert MR. SHANK3, the synapse, and autism. N Engl J Med. 2011;365(2): 173-5. doi:10.1056/NEJMcibr1104261.

40. Wohr M. Ultrasonic vocalizations in Shank mouse models for autism spectrum disorders: detailed spectrographic analyses and developmental profiles. Neurosci Biobehav Rev. 2014;43:199-212. doi:10.1016/j.neubiorev. 2014.03.021.

41. Chattopadhyaya B, Cristo GD. GABAergic circuit dysfunctions in neurodevelopmental disorders. Front Psychiatry. 2012:3:51. doi:10.3389/fpsyt. 2012.00051.

42. Coghlan S, Horder J, Inkster B, Mendez MA, Murphy DG, Nutt DJ. GABA system dysfunction in autism and related disorders: from synapse to symptoms. Neurosci Biobehav Rev. 2012;36(9):2044-55. doi:10.1016/j.neubiorev.2012.07.005.

43. Somogyi $P$, Klausberger T. Defined types of cortical interneurone structure space and spike timing in the hippocampus. J Physiol. 2005;562(Pt 1):9-26. doi:10.1113/jphysiol.2004.078915.

44. Toledo-Rodriguez M, Goodman P, Illic M, Wu C, Markram H. Neuropeptide and calcium-binding protein gene expression profiles predict neuronal anatomical type in the juvenile rat. J Physiol. 2005;567(Pt 2):401-13.

45. Marin O. Interneuron dysfunction in psychiatric disorders. Nat Rev Neurosci. 2012;13(2):107-20. doi:10.1038/nrn3155.

46. Zikopoulos B, Barbas H. Altered neural connectivity in excitatory and inhibitory cortical circuits in autism. Front Hum Neurosci. 2013;7:609. doi:10.3389/fnhum.2013.00609.
47. Gogolla N, Leblanc JJ, Quast KB, Sudhof TC, Fagiolini M, Hensch TK. Common circuit defect of excitatory-inhibitory balance in mouse models of autism. J Neurodev Disord. 2009;1(2):172-81. doi:10.1007/s11689-009-9023-X.

48. Wohr M, Orduz D, Gregory P, Moreno H, Khan U, Vorckel KJ, et al. Lack of parvalbumin in mice leads to behavioral deficits relevant to all human autism core symptoms and related neural morphofunctional abnormalities. Translat Psychiatry. 2015;5, e525. doi:10.1038/tp.2015.19.

49. Caillard O, Moreno H, Schwaller B, Llano I, Celio MR, Marty A. Role of the calcium-binding protein parvalbumin in short-term synaptic plasticity. Proc Natl Acad Sci U S A. 2000;97(24):13372-7.

50. Muller M, Felmy F, Schwaller B, Schneggenburger R. Parvalbumin is a mobile presynaptic $\mathrm{Ca}^{2+}$ buffer in the calyx of held that accelerates the decay of $\mathrm{Ca}^{2+}$ and short-term facilitation. J Neurosci. 2007;27(9):2261-71.

51. Collin T, Chat M, Lucas MG, Moreno H, Racay P, Schwaller B, et al. Developmental changes in parvalbumin regulate presynaptic $\mathrm{Ca}^{2+}$ signaling. J Neurosci. 2005;25(1):96-107.

52. Manseau F, Marinelli S, Mendez P, Schwaller B, Prince DA, Huguenard JR, et al. Desynchronization of neocortical networks by asynchronous release of GABA at autaptic and synaptic contacts from fast-spiking interneurons. PLoS Biol. 2010. doi:10.1371/journal.pbio.1000492.

53. Orduz D, Bischop DP, Schwaller B, Schiffmann SN, Gall D. Parvalbumin tunes spike-timing and efferent short-term plasticity in striatal fast spiking interneurons. J Physiol. 2013;591(Pt 13):3215-32. doi:10.1113/jphysiol.2012.250795.

54. Servais L, Bearzatto B, Schwaller B, Dumont M, De Saedeleer C, Dan B, et al. Mono- and dual-frequency fast cerebellar oscillation in mice lacking parvalbumin and/or calbindin D-28k. Eur J Neurosci. 2005;22(4):861-70.

55. Vreugdenhil M, Jefferys JG, Celio MR, Schwaller B. Parvalbumin-deficiency facilitates repetitive IPSCs and gamma oscillations in the hippocampus. J Neurophysiol. 2003;89(3):1414-22.

56. Schwaller $B$. The use of transgenic mouse models to reveal the functions of $\mathrm{Ca}^{2+}$ buffer proteins in excitable cells. Biochim Biophys Acta. 2012;1820(8): 1294-303. doi:10.1016/j.bbagen.2011.11.008.

57. Schwaller B, Tetko IV, Tandon P, Silveira DC, Vreugdenhil M, Henzi T, et al. Parvalbumin deficiency affects network properties resulting in increased susceptibility to epileptic seizures. Mol Cell Neurosci. 2004; 25(4):650-63.

58. Schwaller B, Dick J, Dhoot G, Carroll S, Vrbova G, Nicotera P, et al. Prolonged contraction-relaxation cycle of fast-twitch muscles in parvalbumin knockout mice. Am J Physiol. 1999;276(2 Pt 1):C395-403.

59. Moreno H, Burghardt NS, Vela-Duarte D, Masciotti J, Hua F, Fenton AA, et al. The absence of the calcium-buffering protein calbindin is associated with faster age-related decline in hippocampal metabolism. Hippocampus. 2012; 22(5):1107-20. doi:10.1002/hipo.20957.

60. West MJ, Slomianka L, Gundersen HJ. Unbiased stereological estimation of the total number of neurons in thesubdivisions of the rat hippocampus using the optical fractionator. Anat Rec. 1991;231(4):482-97. doi:10.1002/ar. 1092310411.

61. Paxinos GFK. The Mouse Brain in Stereotaxic Coordinates. Second Edition. San Diego: Academic; 2001.

62. West MJ, Ostergaard K, Andreassen OA, Finsen B. Estimation of the number of somatostatin neurons in the striatum: an in situ hybridization study using the optical fractionator method. J Comp Neurol. 1996;370(1):11-22. doi:10. 1002/(SICI)1096-9861(19960617)370:1<11\%AID-CNE2>3.0.CO:2-O.

63. Gundersen HJ, Jensen EB, Kieu K, Nielsen J. The efficiency of systematic sampling in stereology-reconsidered. J Microsc. 1999;193(Pt 3):199-211.

64. Livak KJ, Schmittgen TD. Analysis of relative gene expression data using real-time quantitative PCR and the 2(-Delta Delta C(T)) Method. Methods. 2001;25(4):402-8. doi:10.1006/meth.2001.1262.

65. Maetzler W, Stünitz H, Bendfeldt K, Vollenweider F, Schwaller B, Nitsch C. Microcalcification after excitotoxicity is enhanced in transgenic mice expressing parvalbumin in all neurons, may commence in neuronal mitochondria, and undergoes structural modifications over time. Neuropathol Appl Neurobiol. 2009;186(1):78-88.

66. Chen G, Racay P, Bichet S, Celio MR, Eggli P, Schwaller B. Deficiency in parvalbumin, but not in calbindin D-28k upregulates mitochondrial volume and decreases smooth endoplasmic reticulum surface selectively in a peripheral, subplasmalemmal region in the soma of Purkinje cells. Neuroscience. 2006;142(1):97-105.

67. Hartig W, Brauer K, Bruckner G. Wisteria floribunda agglutinin-labelled nets surround parvalbumin-containing neurons. Neuroreport. 1992;3(10): 869-72. 
68. Celio MR, Blümcke I. Perineuronal nets- a specialized form of extracellular matrix in the adult nervous system. Brain Res Rev. 1994;19:128-45.

69. Haunso A, Ibrahim M, Bartsch U, Letiembre M, Celio MR, Menoud P. Morphology of perineuronal nets in tenascin-R and parvalbumin single and double knockout mice. Brain Res. 2000;864(1):142-5.

70. Meyer AH, Katona I, Blatow M, Rozov A, Monyer $\mathrm{H}$. In vivo labeling of parvalbumin-positive interneurons and analysis of electrical coupling in identified neurons. J Neurosci. 2002;22(16):7055-64.

71. Bitanihirwe BK, Woo TU. Perineuronal nets and schizophrenia: the importance of neuronal coatings. Neurosci Biobehav Rev. 2014;45:85-99. doi:10.1016/j.neubiorev.2014.03.018.

72. Selby L, Zhang C, Sun QQ. Major defects in neocortical GABAergic inhibitory circuits in mice lacking the fragile $X$ mental retardation protein. Neurosc Lett. 2007;412(3):227-32. doi:10.1016/j.neulet.2006.11.062.

73. Sadakata T, Washida M, Iwayama Y, Shoji S, Sato Y, Ohkura T, et al. Autistic like phenotypes in Cadps2-knockout mice and aberrant CADPS2 splicing in autistic patients. J Clin Invest. 2007;117(4):931-43. doi:10.1172/JCI29031.

74. Tripathi PP, Sgado P, Scali M, Viaggi C, Casarosa S, Simon HH, et al. Increased susceptibility to kainic acid-induced seizures in Engrailed-2 knockout mice Neuroscience. 2009;159(2):842-9. doi:10.1016/j.neuroscience.2009.01.007.

75. Ellegood J, Anagnostou E, Babineau BA, Crawley JN, Lin L, Genestine M, et al. Clustering autism: using neuroanatomical differences in 26 mouse models to gain insight into the heterogeneity. Mol Psychiatry. 2014;20(1): 118-25. doi:10.1038/mp.2014.98.

76. Gogolla N, Takesian AE, Feng G, Fagiolini M, Hensch TK. Sensory integration in mouse insular cortex reflects GABA circuit maturation. Neuron. 2014;83(4): 894-905. doi:10.1016/j.neuron.2014.06.033.

77. Bockers TM, Segger-Junius M, Iglauer P, Bockmann J, Gundelfinger ED, Kreutz MR, et al. Differential expression and dendritic transcript localization of Shank family members: identification of a dendritic targeting element in the 3' untranslated region of Shank1 mRNA. Mol Cell Neurosci. 2004;26(1): 182-90. doi:10.1016/j.mcn.2004.01.009.

78. Banerjee S, Riordan M, Bhat MA. Genetic aspects of autism spectrum disorders: insights from animal models. Front Cell Neurosci. 2014:8:58. doi:10.3389/fncel.2014.00058.

79. Sebat J, Lakshmi B, Malhotra D, Troge J, Lese-Martin C, Walsh T, et al. Strong association of de novo copy number mutations with autism. Science. 2007; 316(5823):445-9. doi:10.1126/science.1138659.

80. Silverman $\mathrm{J}$, Crawley $\mathrm{JN}$. The promising trajectory of autism therapeutics discovery. Drug Discov Today. 2014;19(7):838-44. doi:10.1016/j.drudis.2013. 12.007.

81. Zeidan-Chulia F, Rybarczyk-Filho JL, Salmina AB, de Oliveira BH, Noda M, Moreira JC. Exploring the multifactorial nature of autism through computational systems biology: calcium and the Rho GTPase RAC1 under the spotlight. Neruomol Med. 2013. doi:10.1007/s12017-013-8224-3.

82. Voineagu I, Wang $X$, Johnston $P$, Lowe JK, Tian $Y$, Horvath S, et al. Transcriptomic analysis of autistic brain reveals convergent molecular pathology. Nature. 2011;474(7351):380-4. doi:10.1038/nature10110.

83. Krey JF, Dolmetsch RE. Molecular mechanisms of autism: a possible role for $\mathrm{Ca}^{2+}$ signaling. Curr Opin Neurobiol. 2007;17(1):112-9. doi:10.1016/j.conb. 2007.01.010. S0959-4388(07)00012-8 [pii].

84. Palmieri L, Papaleo V, Porcelli V, Scarcia P, Gaita L, Sacco R, et al. Altered calcium homeostasis in autism-spectrum disorders: evidence from biochemical and genetic studies of the mitochondrial aspartate/glutamate carrier AGC1. Mol Psychiatry. 2010;15(1):38-52. doi:10.1038/mp.2008.63.

85. Carayol J, Sacco R, Tores F, Rousseau F, Lewin P, Hager J, et al. Converging evidence for an association of ATP2B2 allelic variants with autism in male subjects. Bio Psychiatry. 2011;70(9):880-7. doi:10.1016/j.biopsych.2011.05.020.

86. Stoner R, Chow ML, Boyle MP, Sunkin SM, Mouton PR, Roy S, et al. Patches of disorganization in the neocortex of children with autism. N Engl J Med. 2014;370(13):1209-19. doi:10.1056/NEJMoa1307491.

87. Ye Q, Miao QL. Experience-dependent development of perineuronal nets and chondroitin sulfate proteoglycan receptors in mouse visual cortex. Matrix Bio. 2013;32(6):352-63. doi:10.1016/j.matbio.2013.04.001.

88. Nowicka D, Soulsby S, Skangiel-Kramska J, Glazewski S. Parvalbumincontaining neurons, perineuronal nets and experience-dependent plasticity in murine barrel cortex. Eur J Neurosci. 2009;30(11):2053-63. doi:10.1111/j. 1460-9568.2009.06996.x.

89. Cabungcal JH, Steullet P, Morishita H, Kraftsik R, Cuenod M, Hensch TK, et al. Perineuronal nets protect fast-spiking interneurons against oxidative stress.
Proc Natl Acad Sci U S A. 2013;110(22):9130-5. doi:10.1073/pnas. 1300454110.

90. Belichenko PV, Miklossy J, Belser B, Budka H, Celio MR. Early destruction of the extracellular matrix around parvalbumin- immunoreactive interneurons in Creutzfeldt-Jakob disease. Neurobiol Dis. 1999;6(4):269-79.

91. Hays SA, Huber KM, Gibson JR. Altered neocortical rhythmic activity states in Fmr1 KO mice are due to enhanced mGluR5 signaling and involve changes in excitatory circuitry. J Neurosci. 2011;31(40):14223-34. doi:10.1523/ JNEUROSCI.3157-11.2011.

92. Paluszkiewicz SM, Olmos-Serrano JL, Corbin JG, Huntsman MM. Impaired inhibitory control of cortical synchronization in fragile $X$ syndrome. J Neurophysiol. 2011;106(5):2264-72. doi:10.1152/jn.00421.2011.

93. Zikopoulos B, Barbas $\mathrm{H}$. Changes in prefrontal axons may disrupt the network in autism. J Neurosci. 2010;30(44):14595-609. doi:10.1523/ JNEUROSCI.2257-10.2010

94. Palmen SJ, van Engeland H, Hof PR, Schmitz C. Neuropathological findings in autism. Brain. 2004;127(Pt 12):2572-83. doi:10.1093/brain/awh287.

95. Amaral DG, Schumann CM, Nordahl CW. Neuroanatomy of autism. Trends Neurosci. 2008;31(3):137-45. doi:10.1016/j.tins.2007.12.005.

96. Mao W, Watanabe T, Cho S, Frost JL, Truong T, Zhao X, et al. Shank1 regulates excitatory synaptic transmission in mouse hippocampal parvalbumin-expressing inhibitory interneurons. Eur J Neurosci. 2015:41(8): 1025-35. doi:10.1111/ejn.12877.

97. Eggermann $\mathrm{E}$, Jonas $\mathrm{P}$. How the 'slow' $\mathrm{Ca}^{2+}$ buffer parvalbumin affects transmitter release in nanodomain-coupling regimes. Nat Neurosci. 2012; 15(1):20-2. doi:10.1038/nn.3002

98. Alberi L, Lintas A, Kretz R, Schwaller B, Villa AE. The calcium-binding protein parvalbumin modulates the firing 1 properties of the reticular thalamic nucleus bursting neurons. J Neurophysiol. 2013;109(11):2827-41. doi:10. 1152/jn.00375.2012.

99. Gonzalez-Burgos G, Lewis DA. NMDA receptor hypofunction, parvalbuminpositive neurons, and cortical gamma oscillations in schizophrenia. Schizophr Bull. 2012;38(5):950-7. doi:10.1093/schbul/sbs010.

100. Berridge MJ. Calcium signalling and psychiatric disease: bipolar disorder and schizophrenia. Cell Tissue Res. 2014;357(2):477-92. doi:10.1007/s00441-0141806-z.

101. Lewis DA. Inhibitory neurons in human cortical circuits: substrate for cognitive dysfunction in schizophrenia. Curr Opin Neurobiol. 2014;26:22-6. doi:10.1016/j.conb.2013.11.003.

102. De Rubeis S, He X, Goldberg AP, Poultney CS, Samocha K, Cicek AE, et al. Synaptic, transcriptional and chromatin genes disrupted in autism. Nature. 2014;515(7526):209-15. doi:10.1038/nature13772.

103. Cross-Disorder Group of the Psychiatric Genomics Consortium. Identification of risk loci with shared effects on five major psychiatric disorders: a genome-wide analysis. Lancet. 2013;381(9875):1371-9. doi:10.1016/S01406736(12)62129-1.

104. Schwaller B. The Regulation of a Cell's $\mathrm{Ca}^{2+}$ Signaling Toolkit: The $\mathrm{Ca}^{2+}$ Homeostasome. Adv Exp Med Biol. 2012;740:1-25. doi:10.1007/978-94-0072888-2_1.

105. Delorme R, Ey E, Toro R, Leboyer M, Gillberg C, Bourgeron T. Progress toward treatments for synaptic defects in autism. Nat Med. 2013;19(6):68594. doi:10.1038/nm.3193.

\section{Submit your next manuscript to BioMed Central and we will help you at every step:}

- We accept pre-submission inquiries

- Our selector tool helps you to find the most relevant journal

- We provide round the clock customer support

- Convenient online submission

- Thorough peer review

- Inclusion in PubMed and all major indexing services

- Maximum visibility for your research

Submit your manuscript at www.biomedcentral.com/submit 